\title{
The Puzzle of Asymmetric Effects of Oil: New Results from International Stock Markets*
}

\author{
Sofia B. Ramos ${ }^{\dagger} \quad$ Helena Veiga
}

This Version: January 2011

\begin{abstract}
Previous work has documented that oil price changes have nonlinear effects in the economy and in stock market returns. We show that the nonlinear effects are different depending on whether countries are energy dependent or not. While price soars seem to have a negative effect on the stock markets of oil energy dependent countries, they have a positive effect on the stock markets of oil exporting countries. Stock market returns are negatively affected by oil price volatility in energy dependent countries and positively in oil exporting countries. Moreover, we find bi-directional effects between oil price increases and some oil volatility measures that can be reinforced with volatility feedback. The asymmetric effects found in oil dependent and oil exporting countries seem to fit into the offset mechanism proposed in the literature where oil price shocks interact both with oil price volatility and the economy. The results are also consistent with the finding that oil exporting countries benefit economically from oil price hikes.
\end{abstract}

JEL classification: C23; G15; Q43

Keywords: Asymmetry; International Financial Markets; Oil Prices; Panel Data; Oil Price Volatility.

${ }^{*}$ The authors acknowledge financial support from the Financial Research Centre/UNIDE and from the Spanish Ministry of Education and Science, research projects ECO2009-08100 and MTM2010-17323.

${ }^{\dagger}$ UNIDE, Lisbon University Institute (ISCTE-IUL), Avenida das Forças Armadas, 1600-083 Lisboa, Portugal. Email: sofia.ramos@iscte.pt. Corresponding author.

$\ddagger$ Universidad Carlos III de Madrid (Department of Statistics and Instituto Flores de Lemus), C/ Madrid 126, 28903 Getafe, Spain. UNIDE, Avenida das Forças Armadas, 1600-083 Lisboa, Portugal. 


\section{Introduction}

Between January 2000 and the summer of 2008, the price of oil increased almost five times, to become a cause of considerable concern. Escalating oil prices are likely to endanger the pace of worldwide economic growth. As stock markets are commonly seen as bellwethers of an economy, oil price variations are likely to be reflected in stock market returns (see, e.g., Fama, 1990; Schwert, 1990). ${ }^{1}$ First, because rising oil prices increase the costs of running a business, decreasing profits and margins. Shareholder claims are therefore lower and so the value of firms. Second, there is a direct effect on inflation, because energy is an input for almost all kind of goods and services. Inflation is like a hidden tax that affects the consumption of families, but also affects the discount rate, making the present value of cash flows be affected by oil price changes through several mechanisms.

The literature has found that both oil price hikes and falls are likely to have effects on the economy and stock markets; yet, they are asymmetric (see Basher and Sadorsky, 2006; Cong et al., 2008; Mork, 1989; Mork et al., 1994; Park and Ratti, 2008; Sadorsky, 2008). Oil price hikes have a negative impact on gross domestic product (GDP), but drops in oil prices do not necessarily have a positive impact on output.

Some explanations have been discussed for the asymmetry puzzle such as investment uncertainty or sectoral shift channels. ${ }^{2}$ Bernanke (1983) shows how uncertainty about energy prices may induce firms to postpone investment decisions, because of the uncertainty about future in-

\footnotetext{
${ }^{1}$ See Chen et al. (1986), Ferson and Harvey (1994a), Huang et al. (1996) and Jones and Kaul (1996).

${ }^{2}$ Although other explanations were also supposed to have the potential to explain the oil price macroeconomy relationship, they have been excluded due to the fact that they establish a symmetric relationship between oil price changes and output growth. The symmetric channels are: real balances, the income transfer model, and finally, the potential output model. The real balance effect argues that an increase in oil prices would lead to inflation which lowers the quantity of real balances in the systems (see, for a detailed discussion on the impact of monetary policy Brown and Yücel, 2002; Mork, 1994; Pierce and Enzler, 1974). The income transfer explanation states that an increase of oil prices deteriorates terms of trade for oil importing countries. Thus, there is a wealth transfer from oil importing countries to oil exporting countries, leading to a fall of the purchasing power of firms and households in oil importing countries (see Dohner, 1981; Mork et al., 1994). The potential reduction of output comes from the classic supply-side effect according to which rising oil prices are indicative of the reduced availability of a basic input to production, consequently there is a rise in cost production, and the growth of output and productivity are slowed (see, among others, Abel and Bernanke, 2001; Barro, 1984; Brown and Yücel, 1999; Rasche and Tatom, 1981; Tatom, 1988).
} 
vestment climate. The sectoral shocks (or sectoral shifts) channel advanced by Lilien (1982) and Davis (1987), suggests that unemployment is, in part, the result of resources being reallocated from declining to expanding sectors of the economy. Hamilton (1988a) shows that price shocks can reduce aggregate employment by inducing workers in adversely affected sectors to remain unemployed. Workers rather wait for the improvement of labor conditions in their sector than move to positively affected sectors. It is the magnitude of relative price changes (i.e. large changes in the price of oil, either positive or negative) that matters.

Ferderer (1996) states that if oil price changes affect positively oil price volatility and if oil price volatility has a negative effect on the economy, then those explanations have a potential to explain the asymmetry puzzle. The basic mechanism that creates these asymmetric effects lies in the fact that oil price hikes and falls increase oil price volatility, which has a negative effect on the economy by the uncertainty and sectoral shock channels. On the other hand, the symmetric channels like real balances, income transfers and potential output transfers, impact economic growth in the opposite direction of oil price changes. Therefore, in the case of a price decline, a positive effect on the economy by the symmetric channels offsets the negative effects created via uncertainty and volatility, leading to a nil effect. In turn, oil price hikes negatively affect the economy and these negative effects add to reinforce the negative effects created by oil price volatility and uncertainty, leading to asymmetric effects. His results on oil volatility supported that the uncertainty and sectoral shocks channels offer a partial solution for the asymmetry puzzle. More recently, Elder and Serletis (2010) found that uncertainty about oil prices has tended to depress investment in the U.S. and Loungani (1986) finds that the absolute change in oil prices does a better job at explaining the variation in output growth and argues that this finding is consistent with the sectoral shocks hypothesis.

Our paper departs from the previous literature because first, we use a large sample of countries distinguishing clearly between oil producing countries and oil dependent countries, because the effects of oil price changes are likely to be different across different countries depending on their production and consumption of oil reserves Jones and Kaul (1996). Second, we use more 
refined ways of measuring the nonlinear impact of oil price changes. The majority of the existing studies base their analysis of asymmetry on the traditional dummy variable approach, i.e., they differentiate positive from negative variations (e.g., Basher and Sadorsky, 2006; Sadorsky, 2008; Nandha and Faff, 2008). We use measures that are better at accounting for oil price instability and endogenous price variations.

Third, our approach also deals with oil volatility effects on stock markets. Lee et al. (1995) and Hamilton (1996) state that turbulence in oil prices causes the marginal effect of any given oil price change to be reduced. Therefore, asymmetry might not exist when accounting for oil volatility. Ferderer (1996) shows that part of the asymmetric relationship between oil price changes and output growth found in previous studies can be explained by the economy's response to oil price volatility. Sadorsky (1999) finds that either an oil price change or its volatility has an impact on real stock returns. A major strength of the present paper is that we use several measures of oil price volatility as well as measures of oil asymmetry that take into account oil price volatility.

We also analyze the non-contemporaneity of the asymmetric effects, and the potential interactions between oil price changes and oil volatility. This analysis checks whether there is support for the uncertainty and sectoral shocks channels, since we test if both positive and negative oil price changes rise oil price volatility.

Our study yields new results: in particular, the difference in direction of the asymmetric effects between oil dependent and oil exporting countries. In other words, oil price increases have a negative impact on the stock market returns of oil dependent countries, while for oil exporting countries, the impact is positive. Oil price falls hit negatively the stock market returns of oil dependent countries but their negative impact on the stock markets of oil exporting countries is stronger.

Jones and Kaul (1996) have remarked that oil price hikes in the post war economy were driven by exogenous shocks. Consistently, we find that measures of asymmetry that account for oil price instability or that are able to better extract the exogenous component of oil price 
changes highlight price soars as the important variable for stock markets. It is interesting to note that despite the fact that oil price declines have a strong impact on oil exporting stock markets, they are not so relevant when we account for volatility and endogeneity.

We also find a different direction of the impact of oil price volatility on stock market returns of oil dependent countries and of oil exporting countries. There is a negative impact for oil dependent countries and positive for oil exporting countries, and the result is robust to several measures of oil price volatility. Asymmetric effects persist with oil volatility.

We find that some measures of volatility show volatility persistence, bi-directional relations and rise with oil futures price changes (whether positive or negative). The latter findings substantiate the theories of sectoral changes or uncertainty channels as explanations of the existence of asymmetric effects between oil and the economy (see Ferderer, 1996). We also find evidence of volatility feedback when we use the filtered volatility obtained from a $\operatorname{GARCH}(1,1)$ model.

The asymmetric effects we find in stock markets of oil exporting countries seem to be supported by the offset mechanism proposed by Ferderer (1996), because we find that, first, oil price volatility has a positive effect on stock market returns and second, that stock market returns follow oil price changes. This means that oil price falls increase oil price volatility, generating a positive effect on returns of stock markets, that offsets the negative effects generated by oil price declines. Overall, oil price declines might not affect stock markets of oil exporting countries.

Moreover, the results are also consistent with the empirical evidence from oil exporting countries that shows that those economies have a positive response to oil price shocks (see Mork et al., 1994; Korhonen and Ledyaeva, 2010, for evidence for Norway and for Russia and Canada, respectively).

The structure of this paper is as follows. Section II reviews the literature. Section III presents the research design and describes the data. Section IV describes the methodology. Section V presents the estimation results. Section VI relates asymmetric effects with oil price volatility. Section VII applies a series of robustness tests to the analysis, and Section VIII concludes. 


\section{Review of Literature}

Many papers have investigated if and why oil prices changes affect economic growth and firm value. Hamilton $(1988 \mathrm{a}, \mathrm{b})$ shows that oil shocks affect the macroeconomy primarily by depressing demand for key consumption and investment goods. Soaring oil prices create inflationary pressure in the economy, which works like a hidden tax, reducing the amount of disposable income consumers have left to spend on other goods and services. Bernanke (1983) shows how uncertainty about energy prices may induce firms to postpone investment decisions due to uncertainty about future investment climate, thereby leading to a decline in aggregate output.

In stock markets, the first results were not supportive of oil as a significant factor. Huang et al. (1996), Chen et al. (1986) and Ferson and Harvey (1994a) find that oil futures returns do not have much impact on stock market indices and that there is no reward for oil price risk in stock markets. Jones and Kaul (1996), however, provide evidence that aggregate stock market

returns in the U.S., Canada, Japan and the U.K. are negatively sensitive to the adverse impact of oil price shocks on their economies. More recently, Driesprong et al. (2008) find some predictive power in oil returns.

Finance theory asserts that stock market prices should rationally reflect the impact of news. If so, soaring oil prices increase the costs of running a business, dampening margins, profits and cash flows, the key drivers of stock prices. Conversely, when oil prices fall, the inverse effects should be observed and stock returns should increase. The evidence has been, however, that there are nonlinear effects. Mork (1989) and Mork et al. (1994) find that oil price hikes have a negative impact on GDP, but that falls in oil prices do not necessarily have a positive impact on output or an impact of the same degree.

Ferderer (1996) shows that part of the asymmetric relationship between oil price changes and output growth found in previous studies can be explained by the economic response to oil volatility. Sadorsky (1999) finds that either an oil price change or its volatility has an impact on real stock returns. Moreover, positive oil price changes have a greater impact on economic activities and are better able to explain the forecast error variance of real stock returns than are 
negative price changes. Sajjadur and Serletis (2010) find that oil price volatility has an impact on macroeconomic activity.

Some explanations have been put forward for the asymmetry puzzle. A strand of the literature has tried to link the postponing of irreversible investment decisions caused by oil price hikes. Bernanke (1983) shows that it is ideal for companies to postpone irreversible investment expenditures when they experienced increased uncertainty concerning the future oil price. The tendency of falling energy prices to stimulate output may be dampened if firms are uncertain whether the fall in energy prices is permanent or transitory. Thus, oil price increases tend to postpone investment decisions. Hamilton (1996, p.216) comments that "If that is indeed the mechanism by which oil shocks affect the economy, then a decrease in oil prices would not confer a positive effect on the economy that mirrors the negative consequences of an oil price increase." Ferderer (1996) finds that the behavior of oil volatility is consistent with this explanation and more recently, Elder and Serletis (2010) find that uncertainty about oil prices has tended to depress investment in the United States.

Another explanation comes from the sectoral shocks literature. Loungani (1986) and Davis (1987) argue that oil shocks may cause sectoral shifts with costly allocation of resources. Greater dispersion of sectoral shocks increases the labor reallocation required, which leads to a larger overall unemployment rate. Loungani (1986) finds that the absolute change in oil prices does a better job in explaining variation in output growth and argues that this finding is consistent with sectoral shocks hypothesis.

The monetary channel has also been discussed but the evidence has not been supportive. Ferderer (1996) states that monetary policy will cause output responses to oil price changes to be asymmetric if central banks tighten policy in response to oil price increases but do not pursue expansionary policies in the face of oil price declines. However, he does not find the evidence supportive. More recently, Bachemeier (2008) also finds compelling evidence that monetary policy plays no role in the transmission of shocks to the economy. Using a more refined methodology, he demonstrates that there is no relation between the reaction of individual stock prices to oil 
shocks and to monetary policy shocks in the U.S.

Some works have examined whether these asymmetric effects pertain to stock market returns such as Basher and Sadorsky (2006), Cong et al. (2008), Park and Ratti (2008) and Sadorsky (2008), but they have not focused on whether oil volatility has a role in explaining the asymmetric effects. Oil price volatility is, however, a key element to understand if channels like uncertainty and sectoral reallocations have a bearing in explaining asymmetric effects. Ferderer (1996) asserts that the two necessary conditions for explaining the mechanism that creates the asymmetric

effects are that oil price changes, whether positive or negative, positively affect oil volatility, and that oil volatility (uncertainty) negatively affects the economy. Thus, because oil price declines increase oil volatility, leading to negative effects on the economy, they offset the positive effects generated by oil price declines by the normal channels. Globally, oil price declines have no effect on the economy, while oil price hikes affect it negatively and these negative effects reinforce the negative effects created by oil price volatility. Another important reason is that asymmetry might not exist when we account for oil price volatility, as the turbulence in oil prices causes the marginal effect of any given oil price change to be reduced (see Hamilton, 1996; Lee et al., 1995).

\section{Research Design and Data}

\section{A. Country Data}

Our analysis assumes that stock markets are bellwethers of the economy (Fama, 1990; Schwert, 1990) and as such, the effects of oil price changes are reflected in stock markets. Moreover, we follow the insight of Jones and Kaul (1996, p. 468) that " the effects of oil shocks are likely to vary considerably across different countries depending on their production and consumption of oil reserves". Thus stock markets should respond differently to oil price changes depending on a country's being self-sufficient, or not, in oil.

We need therefore to select a set of countries that are widely dependent on oil and another set of countries that are self-sufficient. Using BP-Statistics (2010), we select a set of countries that 
are only oil consumers and have no production of oil. These countries will be labeled the sample of oil dependent countries, i.e., they have no production that satisfies domestic consumption. Next, we need a set of countries with the opposite features. Hence, we look at the group of oil producing countries, but not all countries in this group have enough production to satisfy their needs. This is the case of the U.S., Australia, the U.K. or even Brazil, although this one has been increasing its production. They are large producers but they still need to import oil to satisfy their domestic needs. Since we want two distinct samples, we select only countries that are self-sufficient in oil, i.e., their consumption is inferior to their production.

As explained before, the sample of countries needs to be intrinsically different. Despite a country's being a producer, the economic effects of oil price hikes might be negative because the country still needs to import energy to grow. The effects of oil price changes might balance out in the economy of countries that are both producers and importers.

The final sample is conditional on the availability of stock market data. This is a problem because many important oil producers do not have well developed stock markets, such as the Gulf countries, among others.

The final sample includes 18 countries. Oil dependent countries are: Austria, Belgium, Finland, France, Germany, Greece, Ireland, Japan, the Netherlands, Portugal, Spain, Sweden and Switzerland. Oil exporting countries are Canada, Colombia, Mexico, Norway and Russia. ${ }^{3}$ Figure 1 shows net oil production for oil exporting countries and consumption for oil dependent countries. Russia had a large growth as a producer among the oil producing countries. Japan and Germany are among the largest oil consumers of the sample of oil dependent countries, being also among the largest economies of the world.

We collect monthly returns for country indices from Datastream, which provides extensive coverage of countries' total market capitalization. Datastream indexes are weighted by market capitalization.

Our sample covers 18 countries from December 1988 through June 2009, for a total of 247

\footnotetext{
${ }^{3}$ Gulf countries for instance have very incipient stock markets.
} 
monthly observations. This is an unbalanced panel because data are not available every month for all countries. Returns are expressed in U.S. dollars. The choice of U.S. dollars as the reference currency is justified by the fact that the price of oil is determined in U.S. dollars in international markets. The stock market variables are the logarithmic changes of the local market portfolio excess returns (index). Returns are in excess of a short-term interest rate, the one-month Eurodollar interest rate as in Ferson and Harvey (1994a).

Table I, Panels A.1 and A.2, reports the summary statistics for stock market indexes by country. Most countries have positive excess returns during the period. Only Belgium, Japan, Portugal and Colombia indexes have negative excess returns. Volatility is lower in Switzerland and France, with values ranging between $4 \%$ and 5\%, and higher in Russia and Greece, 14.5\% and $10.0 \%$, respectively. All countries have kurtosis values higher than three. We also observe that the distribution of excess returns is negatively skewed for the majority of the countries; only two present positive skewness. Consequently, the assumption of Gaussian returns is rejected by the Jarque-Bera test for almost all countries, except Japan.

\section{B. Oil Prices}

Oil prices are from the settlement price of the NYMEX oil futures contract, the most widely traded futures contract on oil. The underlying asset is the West Texas Intermediate oil, a light crude oil widely used as a current benchmark for U.S. crude production. ${ }^{4}$ Prices are in U.S. dollars per barrel (U\$/BBL). The variable (oil) is the logarithmic difference of oil prices.

Summary statistics about the time series are displayed in Table I, Panel B. The oil returns register a positive mean during the period, around $0.6 \%$ monthly, with a standard deviation of almost $10 \%$ monthly.

Figure 2 depicts the oil price index and oil returns over the sample period. In the first graph, the price of oil fluctuates little until around 1998. There is some turbulence in the summer of 1990, which coincides with the beginning of the invasion of Kuwait and the Gulf War, but prices

\footnotetext{
${ }^{4}$ In the robustness analysis we use London Brent Crude Oil Prices.
} 
drop to normal levels after the end of the war in February 1992. In 1999, prices rise again, but then drop after 2000 and 2001. Then they rose to over \$50/BBL in 2005, 100\$/BBL in 2007 and almost $\$ 150$ / BBL in July 2008. As many countries worldwide experienced economic recession, prices continued to slide until the end of 2008, to peak again during 2009. The value in June 2009 was again close to $\$ 70 / \mathrm{BBL}$.

The second graph in Figure 2 depicts the variations in oil prices. Many large monthly variations are visible, as great as $+/-20 \%$. There are four large declines in prices that correspond to December 1990 and January 1991, the end of the Gulf War; December 2000; March 2003 and more recently October and December 2008. Price spikes can be seen in July, August and September of 1990, the beginning of the Gulf War; March 1999; May 2000; March 2002; January 2005 and May 2009.

\section{Oil Price Volatility}

We also analyze the exposure to oil volatility. Ferderer (1996) showed that oil volatility accounted for some of the asymmetric effects in the economy. To do that we define several volatility measures. The first is provided by Schwert (1989) $\left(\hat{\sigma}_{\text {schwert }}\right)$ and consists in the absolute value of the residuals obtained by fitting an autoregressive model to oil futures returns, that is,

$$
o i l_{t}=\alpha+\sum_{i=1}^{L} \phi_{i} o i l_{t-i}+u_{t}
$$

where $u_{t}$ follows a normal distribution with mean zero and variance $\psi^{2}$. The model is estimated by OLS and the regression lag length (L) is determined by the usual significance tests. In our case $L=1$. The volatility is then the absolute value of the regression residuals, $\hat{u}_{t}$, which corresponds to an estimate of the conditional variance of oil futures returns.

The second measure also lies in the estimation of an autoregressive model, but we apply a moving average to the squared residuals obtained by fitting the previous model to oil futures 
returns:

$$
\hat{\sigma}_{\text {gallant }_{t}}=\left[(m+1)^{-1} \sum_{j=0}^{m} \hat{\epsilon}_{t-j}^{2}\right]^{0.5}
$$

(see Gallant and Tauchen, 1998). Instead of considering a single residual in the calculation of volatility, with this method we weight the neighboring residuals. This method of estimation is typically used when the first two conditional moments are evaluated (see Bansal and Zhou, 2002; Doran and Ronn, 2008; Durham, 2003).

The third measure is the filtered volatility from a $\operatorname{GARCH}(1,1)$ model $\left(\hat{\sigma}_{\text {garch }}\right)$ given by

$$
\begin{aligned}
O I L_{t} & =\mu+\sigma_{t} \epsilon_{t} \\
\sigma_{t}^{2} & =\alpha_{0}+\alpha_{1} \epsilon_{t-1}^{2}+\beta_{1} \sigma_{t-1}^{2},
\end{aligned}
$$

where $\varepsilon_{t}=\sigma_{t} \epsilon_{t}$ is the prediction error, $\sigma_{t}>0$ is the conditional standard deviation of the underlying oil return (denoted volatility) and the innovation $\epsilon_{t} \sim N I D(0,1)$. We impose the conditions $\alpha_{0}>0, \alpha_{1} \geq 0$ and $\beta_{1} \geq 0$ to guarantee that the conditional variance is positive and $\alpha_{1}+\beta_{1}<1$ to assure its stationarity. Finally, the fourth measure is the squared value of oil futures returns which we denote $\hat{\sigma}_{\text {square }}$.

Volatility measures are presented in Figure 3 and Table I and the correlations among them in Table II. Oil volatility is negatively correlated with oil and the correlations among them is not so high. $\hat{\sigma}_{\text {schwert }}$ is highly correlated with $\hat{\sigma}_{\text {square }}$ and $\hat{\sigma}_{\text {gallant }}$ is highly correlated with $\hat{\sigma}_{\text {garch }}$. In Figure 3, we observe the patterns of these four volatility measures: $\hat{\sigma}_{\text {gallant }}$ and $\hat{\sigma}_{\text {garch }}$ show smoother volatility patterns while $\hat{\sigma}_{\text {schwert }}$ and $\hat{\sigma}_{\text {square }}$ present a more erratic pattern.

\section{Other Variables}

Following Stulz (1981) and Adler and Dumas (1983), one factor is the world market portfolio. Datastream provides a world market index which is computed by weighting all country index returns. The variable world is the logarithm of changes of the world market portfolio index in excess of a short-term interest rate, the one-month Eurodollar interest rate as in Ferson and 
Harvey (1994a). Empirically this proxy of the market portfolio has been tested in papers such as Ferson and Harvey (1994b), Basher and Sadorsky (2006) and Nandha and Faff (2008). Panel B of Table I reports summary statistics for the independent variables. For the variable world we see a negative excess return as well as negative skewness. The Jarque-Bera test rejects the null hypothesis of normal returns.

Adler and Dumas (1983) also present theoretical support for the pricing of exchange rate fluctuations in a global setting. Solnik (1974) model advocates that exchange rate risk should be priced in the absence of purchasing power parity. Therefore, we test whether a country index exhibits sensitivity to currency rate changes, in particular, we test whether excess returns of the stock market of country $i$ show some sensitivity to changes in currency rates against the U.S. dollar. Dumas and Solnik (1995) and De Santis and Gerard (1998) find that currency risk is priced in a conditional setting for aggregate market returns.

currency is the logarithmic change in currency rates against the U.S. dollar. As all bilateral rates are expressed in U.S. dollars per unit of the foreign currency, a positive change in the rate means the foreign currency appreciated with respect to U.S. dollars. In Panel B are summary statistics for currency rates. Seven of the eighteen currencies have depreciated against the U.S. dollar. Currency rates present low volatility. Overall, we observe that exchange rate variability is on average lower than the volatility of stock index returns. Since kurtosis is higher than three and there is negative skewness, the Jarque-Bera test lead us to reject the null of Gaussian returns.

\section{Methodology}

To test for asymmetric effects of oil price variation, we need to define nonlinear measures of oil price changes. The traditional approach is based on a dummy variable that differentiates positive from negative oil price variations and multiplies the variable oil price changes, which is 
equivalent to the following variables:

$$
\begin{aligned}
& \text { oilp }_{t}=\max \left(0, \text { oil }_{t}\right) \\
& \text { oiln }_{t}=\min \left(0, \text { oil }_{t}\right),
\end{aligned}
$$

at time $t$, the variable oilp (oiln) assumes positive values each time variations are positive (negative) and zero otherwise.

Following former studies, we use the following specification to test for asymmetry. ${ }^{5}$

$$
\begin{array}{r}
\text { index }_{i, t}=\alpha_{i}+\beta_{\text {world }} \cdot \text { world }_{t}+\beta_{\text {curr }} \cdot \text { currency }_{i, t}+\beta_{\text {oilp }} \cdot \text { oilp }_{t}+\beta_{\text {oiln }} \cdot \text { oiln }_{t} \\
+\beta_{\text {oilp }}^{\prime} \cdot \text { oilp }_{t} \cdot \text { export }+\beta_{\text {oiln }}^{\prime} \cdot \text { oiln }_{t} \cdot \text { export }+u_{i, t},
\end{array}
$$

where the dependent variable is the excess returns of the stock market of country $i$ at time $t$ $\left(\right.$ inde $\left._{i, t}\right)$. The independent variables are the world market excess return on a risk-free rate at time $t\left(\right.$ world $\left._{t}\right)$; the currency rate variations of country $i$ at time $t$ (currency $\left.i, t\right)$ and oilp and oiln are variables that assume positive and negative variations of oil prices. $\alpha_{i}$, the intercept, accounts for possible heterogeneity among countries and is constant over time. This means that the effect of a change in one explanatory variable is the same for all countries and all periods, but the average level for country $i$ may be different from that of country $j . u_{i, t}$ is the error of country $i$ at time $t$ and represents the non-systematic excess returns relative to the factors.

To test our hypothesis we define a dummy variable export that interacts with oilp and oiln. This dummy variable is one if the country is an exporter of oil and zero otherwise. If oil exporting countries have a different sensitivity to oil price changes we expect the coefficient of the interaction variables to be statistically significant.

To test if oil has asymmetric effects, we define the null hypothesis of symmetry $H_{01}: \beta_{\text {oilp }}=$ $\beta_{\text {oiln. }}$. Asymmetry implies the rejection of the null. Notice that the null is not rejected if the two coefficients were not significant, i.e., if oil had no significant effects on stock markets, we could conclude for symmetry. To account for this possibility a second hypothesis is formulated

\footnotetext{
${ }^{5}$ According to Ferson and Harvey (1994b), factor model regressions provide information about the usefulness of global factors in controlling for the risks of international investments.
} 
$H_{02}: \beta_{\text {oilp }}=0$ and $\beta_{\text {oiln }}=0$. Asymmetry is therefore confirmed by the rejection of the two null hypotheses: $H_{01}$ and $H_{02}$.

Asymmetry is also checked using a measure developed by Lee et al. (1995) called scaled oil price increases $(s o p i)$. According to these authors what matters is how surprising is an oil price increase based on the observed changes. An unexpected oil price change will have less of an impact when conditional variances are large because much of the change in oil price will be regarded as transitory.

In order to calculate this measure we estimate a $\operatorname{GARCH}(1,1)$ model similar to the one presented in the previous subsection. Therefore, a measure that does reflect the size and the variability of the unexpected oil shock might be defined as $\hat{\varepsilon}_{t}^{*}=\frac{\hat{\varepsilon}_{t}}{\hat{\sigma}_{t}}$ and consequently sopi at time $t$ is given by:

$$
\operatorname{sopi}_{t}=\max \left(0, \hat{\varepsilon}_{t}^{*}\right) \text {. }
$$

In a similar manner the scaled oil price declines $(\operatorname{sopd})$ at time $t$ is defined as $\operatorname{sopd} d_{t}=\min \left(0, \hat{\varepsilon}_{t}^{*}\right)$. Therefore, oil price increases and decreases are scaled by the oil conditional standard deviation. sopi and sopd will be large (in absolute value) when the oil innovation is large (in absolute value). Figure 4 graphs sopi and sopd. The figure has some similarities with returns (Figure 2), but we also see some differences, namely the variables sopi and sopd have a more shrinking scale, due to the standardization.

In a similar way, the following specification also tests for nonlinear effects of oil.

$$
\begin{aligned}
\text { index }_{i, t}= & \alpha_{i}+\beta_{\text {world }} \cdot \text { world }_{t}+\beta_{\text {curr }} \cdot \text { currency }_{i, t}+\beta_{\text {sopi }} \cdot \text { sopi }_{t}+\beta_{\text {sopd }} \cdot \text { sopd }_{t}+ \\
& +\beta_{\text {sopi }}^{\prime} \cdot \operatorname{sopi}_{t} \cdot \text { export }+\beta_{\text {sopd }}^{\prime} \cdot \operatorname{sopd}_{t} \cdot \text { export }+u_{i, t}
\end{aligned}
$$

sopi and sopd will capture the asymmetric effects. We also use an interaction variable (export) that will account for differences between oil dependent countries and oil exporting countries.

The third measure was proposed in Hamilton (1996). He argues that if one wants to measure how unsettling an increase in the price of oil is likely to be for the spending decisions of consumers 
and firms, it is more appropriate to compare the current price of oil with its value over the last year rather than during the previous month alone. Net oil price increase (nopi) at time $t$ is defined as:

$$
n o p i_{t}=\max \left(0, \ln \left(p_{-} o i l_{t}\right)-\ln \left(\max \left(p_{-} o i l_{t-1}, \ldots, p_{-} o i l_{t-12}\right)\right)\right) .
$$

nopi can be interpreted as the amount by which the log oil futures price exceeds its maximum value over the last year (here, p_oil is used for oil futures price). Note that in a period of consistent oil price escalation, nopi would be small, but if prices soar sharply then nopi is high. An advantage of nopi is that it is a better measure to extract the exogenous component of oil price fluctuations (see Kilian, 2008). Similarly we define net oil price decline (nopd) at time $t$ as $n o p d_{t}=\min \left(0, \ln \left(p_{-} o i l_{t}\right)-\ln \left(\max \left(p_{-} o i l_{t-1}, \ldots, p_{-} o i l_{t-12}\right)\right)\right)$. nopd is negative when oil prices are below its peak value over the last year. ${ }^{6}$

Figure 5 plots nopi and nopd for the sample period December 30, 1988 to June 30, 2009. We see episodes of peaking prices that seem to cluster in some periods of time. nopd also has some peaks and slumps, and we can see the dramatic fall of oil futures prices during 2009. A similar approach is used to test asymmetry and differences between oil exporting and oil dependent countries.

$$
\begin{aligned}
\text { index }_{i, t}= & \alpha_{i}+\beta_{\text {world }} \cdot \text { world }_{t}+\beta_{\text {curr }} \cdot \text { currency }_{i, t}+\beta_{\text {nopi }} \cdot \text { nopi }_{t}+\beta_{\text {nopd }} \cdot \text { nopd }_{t}+ \\
& \beta_{\text {nopi }}^{\prime} \cdot \text { nopi }_{t} \cdot \text { export }+\beta_{\text {nopd }}^{\prime} \cdot \text { nopd }_{t} \cdot \text { export }+u_{i, t} .
\end{aligned}
$$

Given the structure of the data, we estimate (1)-(3) using panel data techniques. One advantage of this approach is that it enhances the quality and quantity of data and allows studying the dynamics of the variable of interest with a relatively short time series. Moreover, intercepts can differ according to country for capturing cross-sectional heterogeneity.

To test the previous equations, we estimate fixed and random effects panels. Although results are quite similar, the Hausman test indicates that the fixed effects specification is often more

\footnotetext{
${ }^{6}$ These measures have been frequently used to measure the impact of oil on macroeconomic variables and more recently stock markets indexes (see, e.g., Aloui and Jammazi, 2009; Cong et al., 2008; Cobo-Reyes and Quirós, 2005; Cuñado and Garcia, 2003; Cologni and Manera, 2008; Park and Ratti, 2008; Ramos and Veiga, 2010).
} 
appropriate. Therefore, hereafter we present estimation results for the fixed effects models whose errors are clustered by country.

\section{Empirical Results}

In this section, we analyze whether oil has asymmetric effects on the sample of countries by estimating (1), (2) and (3). Second, we analyze whether oil volatility accounts for the oil asymmetric effects by including this variable into the model. Third, we extend the analysis to examine whether oil has asymmetric effects on sector market returns.

\section{A. Asymmetric effects of oil price changes in stock markets}

Table III shows the estimation results of (1), (2) and (3). Coefficients of the variables world and currency are statistically significant. The coefficient of the variable world is close to one. Therefore the International-Capital Asset Pricing Model (I-CAPM) cannot be rejected. Second, the variable currency is statistically significant and has a positive coefficient as in the results of Carrieri and Majerbi (2006). This means that appreciations of the local currency against the U.S. dollar have a positive effect on stock market returns.

The results are consistent with a conjecture of nonlinear effects for oil dependent countries. Column (1) uses dummy variables to test responses to positive and negative variations. The coefficient of $\beta_{\text {oilp }}$ is negative and $\beta_{\text {oiln }}$ is positive, and both variables are statistically significant at standard levels of confidence. The sign of the coefficients suggests that when oil prices soar, stock market returns drop, but when oil prices fall, stock markets do not climb; rather stock returns are again likely to drop. Note also that the magnitude of positive variations is larger than negative ones.

Interaction variables are also statistically significant. The coefficients of oilp for exporting countries is positive $(-0.092+0.174=0.082)$ and for oiln positive too $(0.0394+0.104=0.1434)$, indicating that stock market returns of exporters follow oil price variations, but the coefficient is 
steeper for oil price falls.

Column (2) uses sopi and sopd to measure the nonlinear effects. Only sopi is statistically significant at standard levels of confidence for oil dependent countries and has a negative coefficient. For oil exporting countries, price soars have a statistically significant positive effect $(-0.895+1.673=0.778)$, but price declines are not statistically significant. Therefore when accounting for instability in prices, only price hikes seem to matter for stock returns.

Column (3) uses nopi and nopd to measure asymmetric effects. nopi has a negative coefficient for oil dependent countries. For oil exporters, the coefficient is positive $(-0.111+0.211=0.1)$. nopd is not statistically significance for oil exporting countries and is only statistically significant at a weaker level of significance for oil dependent countries. Once again oil price hikes show a larger impact than falls.

The results show different asymmetric effects for stock markets of oil dependent and oil exporting countries. Oil price hikes have a negative impact on stock markets of oil dependent countries, while for oil exporters the impact is positive. Oil price falls hit negatively stock markets of oil dependent countries but stock market returns of oil exporters plunge even more.

Measures of asymmetry that account for oil price instability or that are able to better extract the exogenous component of oil price changes indicate statistical significance only for oil price hikes. Note that, despite the fact that oil price declines have a strong impact on oil exporting stock markets, they became statistically insignificant when we account for volatility and endogeneity. Second, results contrast with the large magnitude of nopi as shown in Figure 4, but are consistent with the fact that oil prices hikes being driven by exogenous shocks (Jones and Kaul, 1996), and that price declines might be only corrections to price hikes.

\section{B. Asymmetric Effects and Oil Price Volatility}

Table IV shows the results of introducing oil price volatility measures in (1), (2) and (3). Columns (1) - (4) show results for oilp and oiln as asymmetry measures and columns (5)-(8) for nopi and 
nopd. ${ }^{7}$ To keep the paper self-contained, we will just briefly analyze the coefficients of oilp and oiln and nopi and nopd.

Oil price volatility has a negative effect on the stock market returns of oil dependent countries. $\hat{\sigma}_{\text {garch }}$ and $\hat{\sigma}_{\text {gallant }}$ are statistically significant at $5 \%$ and present negative coefficients and $\hat{\sigma}_{\text {schwert }}$ and $\hat{\sigma}_{\text {square }}$ are statistically significant at $10 \%$. Interestingly, when oil volatility interacts with the export dummy, the sign is reversed and the coefficient becomes positive for countries. Thus, oil price volatility impacts positively the stock market returns of oil exporting countries.

These asymmetric results persist for oil dependent countries as shown in columns (2) and (3), when $\hat{\sigma}_{\text {garch }}$ and $\hat{\sigma}_{\text {gallant }}$ are in the model. For oil exporting countries, all the variables are statistically significant at standard levels of confidence, meaning that oilp and oiln are different for those countries. ${ }^{8}$ Only $\hat{\sigma}_{\text {square }}$ eliminates asymmetry.

Using nopi and nopd, we verify again that only nopi is statistically significant both for oil dependent and oil exporting countries. The impact of past positive variations is positive for oil dependent countries, and the sign is reversed for oil exporting countries.

\section{Asymmetric effects of oil price changes in sectors}

The previous section has documented that nonlinear effects exist for stock markets of oil dependent countries and for oil exporting countries. One could ask if the results we find could be driven by the weight that the oil and gas sector has on stock markets of the sample of exporter countries.

To better analyze this issue, we investigate the existence of nonlinear effects by sector. We use the industrial decomposition of Datastream, and use 10 sectors from Level 2. The sectors are: Basic materials (basicmat), Consumer goods (consgood), Consumer Services (consserv), Financials (financials), Health Care (healthcare), Industrials (industrials), Oil and Gas (oilgas), technology (technology), Telecommunications (telecom) and Utilities (utilities).

\footnotetext{
${ }^{7}$ This table does not present sopi and sopd as these measures already account for volatility.

${ }^{8}$ Ferderer (1996) states that if coefficients become insignificant when oil volatility is introduced then the evidence supports sectoral shocks and uncertainty channel as an explanation for the asymmetry puzzle.
} 
As shown by Ramos and Veiga (2010), oil and gas industry returns tend to follow oil price changes, but for other sectors it is most likely that oil price changes have a negative impact.

Equations (1), (2) and (3) are used to explain the returns of sectors instead of country stock market returns. This allow us to see whether the non-oil related sectors have a different response to oil price changes and whether the asymmetry is driven by the weight that the oil and gas sector might have in stock markets.

Results are presented in Table V. For the sake of brevity we present only the results of the coefficients of interest. Looking at oilp and oiln, we can analyze the results for sectors of oil dependent countries. oilp has a negative coefficient for all sectors except for oil and gas. oiln has a positive coefficient for a large number of sectors, including the oil and gas industry. Thus, the results for oil dependent countries are similar to those of Table III.

The interaction variable shows how the sector returns are affected in oil exporting countries. The coefficient of the interaction variable is for almost sectors positive for oilp, confirming the general trend of sign switching, making oil price hikes affect positively the returns of non-oil related sectors in those countries. For oiln the interaction variable is almost never statistically significant. Thus again oil price effects are asymmetric.

The results are confirmed using other asymmetry measures. Panel B uses sopi and sopd as asymmetry measures. sopi has a negative coefficient and sopd a positive coefficient. For oil exporting countries sopi export is statistically significant and its coefficient has a positive sign, while sopd $\cdot$ export is not statistically significant. The results and tests validate the evidence that asymmetric effects are different for oil dependent and oil exporting countries. Panel C uses nopi and nopd and again the sign of nopi tends to be of opposite sign for sectors of oil exporting countries.

Table VI shows the results with oil price volatility in (1), (2) and (3). We keep oilp and oiln as the asymmetry measures. Panels A-D use different volatility measures $\hat{\sigma}_{\text {garch }}, \hat{\sigma}_{\text {gallant }}, \hat{\sigma}_{\text {schwert }}$ and $\hat{\sigma}_{\text {square }}$. Oil price volatility has a negative effects on sector returns for oil dependent countries. The interaction variable shows that the sign of the coefficient of oil volatility is reversed for many 
sectors for oil exporting countries.

Overall, the results show that it is not the weight of the oil and gas sector in oil exporting countries that is driving the results and non-oil related sector returns seem also to follow oil price changes in oil exporting countries.

\section{Asymmetric impacts and transmissions between mar- kets}

So far we have documented that oil price changes have asymmetric effects on international stock market returns. One important related issue is whether positive and negative oil futures price variations affect oil price volatility. To examine this relation, we use the four measures of volatility defined in Section III.C and we estimate the following VAR model:

$$
\begin{aligned}
{\left[\begin{array}{c}
\ln \left(\hat{\sigma}_{\text {oil }_{t}}\right) \\
\ln \left(\text { oilp }_{t}\right) \\
\text { oiln }_{t}
\end{array}\right]=} & {\left[\begin{array}{c}
\mu_{1} \\
\mu_{2} \\
\mu_{3}
\end{array}\right]+\left[\begin{array}{ccc}
\phi_{11}^{(1)} & \phi_{12}^{(1)} & \phi_{13}^{(1)} \\
\phi_{21}^{(1)} & \phi_{22}^{(1)} & \phi_{23}^{(1)} \\
\phi_{31}^{(1)} & \phi_{32}^{(1)} & \phi_{33}^{(1)}
\end{array}\right]\left[\begin{array}{c}
\ln \left(\hat{\sigma}_{o i l_{t-1}}\right) \\
\ln \left(\text { oilp }_{t-1}\right) \\
\text { oiln }_{t-1}
\end{array}\right]+} \\
& {\left[\begin{array}{ccc}
\phi_{11}^{(2)} & \phi_{12}^{(2)} & \phi_{13}^{(2)} \\
\phi_{21}^{(2)} & \phi_{22}^{(2)} & \phi_{23}^{(2)} \\
\phi_{31}^{(2)} & \phi_{32}^{(2)} & \phi_{33}^{(2)}
\end{array}\right]\left[\begin{array}{c}
\ln \left(\hat{\sigma}_{o i l_{t-2}}\right) \\
\ln \left(\text { oilp }_{t-2}\right) \\
\text { oiln }_{t-2}
\end{array}\right]+\underbrace{\left[\begin{array}{c}
u_{1 t} \\
u_{2 t} \\
u_{3 t}
\end{array}\right]}_{u_{t}}, }
\end{aligned}
$$

where

$$
E\left(u_{t}\right)=0, \quad E\left(u_{s} u_{t}^{\prime}\right)= \begin{cases}\Sigma_{u} & \text { for } s=t \\ 0 & \text { for } s \neq t\end{cases}
$$

We use $\hat{\sigma}_{\text {oil }}$ as a general concept to denote the four measures of volatility $\left(\hat{\sigma}_{\text {schwert }}, \hat{\sigma}_{\text {gallant }}, \hat{\sigma}_{\text {garch }}\right.$ and $\left.\hat{\sigma}_{\text {square }}\right)$.

Equation (4) allows modeling the conditional volatilities and asymmetry between oil futures returns. We specify conditional volatility and oilp as exponential functions to guarantee their positivity (see Amira et al., 2009). To exemplify, the first equation of model (4) using the 
volatility measure $\hat{\sigma}_{\text {schwert }}$ is

$$
\begin{aligned}
\ln \left(\hat{\sigma}_{\text {schwert }_{t}}\right) & =\mu_{1}+\phi_{11}^{(1)} \hat{\sigma}_{\text {schwert }_{t-1}}+\phi_{12}^{(1)} \ln \left(\text { oilp }_{t-1}\right)+\phi_{13}^{(1)} \text { oiln }_{t-1} \\
& +\phi_{11}^{(2)} \hat{\sigma}_{\text {schwert }_{t-2}}+\phi_{12}^{(2)} \ln \left(\text { oilp }_{t-2}\right)+\phi_{13}^{(2)} \text { oiln }_{t-2}+u_{1 t} .
\end{aligned}
$$

This equation represents a stochastic model for volatility that is a function of its past, the past of positive and negative variations of oil futures returns and an error $u_{1}$. The impact of oilp on oil volatility is captured by the coefficients $\phi_{12}^{(1)}$ and $\phi_{12}^{(2)}$. Similarly, the impact of oiln on oil volatility is captured by the coefficients $\phi_{13}^{(1)}$ and $\phi_{13}^{(2)}$. The second and third equations of the VAR(2) model describe the dynamics of the positive and negative variations of oil futures prices, respectively. Moreover, we assume that the errors of the model are serially uncorrelated, but they may be correlated with each other contemporaneously and at various leads and lags.

Table VII displays the estimation results of model (4). The results are different for different measures of volatility. $\hat{\sigma}_{\text {schwert }}$ and $\hat{\sigma}_{\text {square }}$ are negatively affected by past negative variations of oil futures prices but they do not affect oilp or oiln. Second, $\hat{\sigma}_{\text {gallant }}$ is affected positively by past values of oilp and oiln, this latter at weak significance levels, but it does not affect oilp and oiln. If we use $\hat{\sigma}_{\text {garch }}$ we observe stronger interactions, i.e., past values of oilp and oiln affect volatility and past values of volatility affect oilp and oiln. Finally and not less important, $\hat{\sigma}_{\text {gallant }}$ and $\hat{\sigma}_{\text {garch }}$ show volatility persistence, i.e, periods of high turbulence in oil prices are likely to persist.

Next, we perform Granger causality Wald tests and Table VIII reports the results of the tests. Regarding volatility measure $\hat{\sigma}_{\text {schwert }}$ we observe that it is Granger-caused by oiln, but oiln and oilp are not Granger-caused by this measure of volatility. The results for volatility measures $\hat{\sigma}_{\text {gallant }}$ and $\hat{\sigma}_{\text {garch }}$ are similar. Both measures are Granger-caused by oilp, and oiln and oilp are Granger-caused by these measures of volatility. Finally, in the case of $\hat{\sigma}_{\text {square }}$ we do not find any type of Granger causality.

This analysis provides interesting insights. We find that oil volatility rises in response both to oil price increases and decreases, considering $\hat{\sigma}_{\text {gallant }}$ and $\hat{\sigma}_{\text {garch }}$, and the magnitude of the volatility rise is reinforced when there are oil price hikes. 
It is also interesting to note the differences in the obtained results due to different measures of volatility. Using $\hat{\sigma}_{\text {gallant }}$ and $\hat{\sigma}_{\text {garch }}$ we are led to conclude that oil volatility is persistent and that these two measures register bi-directional effects, that is, they are affected by past values of positive and negative oil futures price variations and their past values affect positive or/and negative oil price futures variations, creating a self-feeding process which does not exist in the case of $\hat{\sigma}_{\text {schwert }}$ and $\hat{\sigma}_{\text {square }}$. These bi-directional effects may be reinforced by the existence of oil volatility feedback. Volatility feedback is supported by volatility persistence. According to the volatility feedback theory, large oil positive or negative shocks increase present and future volatility, leading to a decrease of stock and futures prices, and consequently to more volatility (see Bekaert and $\mathrm{Wu}, 2000$ ). Volatility feedback seems to be present when we use $\hat{\sigma}_{\text {garch }}$ and it is also for this measure that we observe stronger bi-directional effects (see estimation results presented in Table VII and Granger causality tests in Table VIII).

\section{Robustness Analysis}

We see whether the results are kept using other specifications. First we confirm the results using a different proxy for oil price, the London Brent crude oil price. Then we analyze separately subsamples of oil dependent and oil-exporting countries.

\section{A. Oil Spot prices}

In this subsection we use the price index of London Brent Crude Oil priced in $\mathrm{U} \$ / \mathrm{BBL}$ to see if results are sensitive to the choice of oil proxy. Measures of oil price asymmetry and oil price volatility are recomputed using the price index of London Brent Crude Oil priced in U\$/BBL. The results are presented in Tables IX and X.

The main findings are kept: oil price changes have asymmetric effects on oil dependent countries, stock market returns of oil dependent countries follow oil prices and oil price volatility has a negative coefficient for oil dependent countries, but the sign is reversed for oil exporting 
countries.

\section{B. Subsamples}

We check whether the results are robust to a change in the methodology. Instead of using a dummy variable to differentiate oil exporting countries, we divide the countries into two subsamples. Table XI shows that oil dependent countries show asymmetric effects, whatever is the measure we use and that positive variations have a larger impact than negative ones. For oil exporting countries, the results confirm stock returns follow oil price returns. Although negative variations have larger coefficients, indicating that stock markets of oil exporting countries are more hit by price falls, statistically, the difference in coefficients is only confirmed for model (4). Table XII introduces oil price volatility. Oil price volatility is statistically significant only at weaker levels of significance and its coefficient is negative for oil dependent countries. For oil exporters, oil price volatility is statistically significant and its coefficient positive.

\section{Conclusion}

We have documented several new facts about the influence of oil price fluctuations in international stock markets by analyzing 18 stock markets over the period 1988-2009. First, oil price changes have nonlinear effects but they are different for oil dependent and oil exporting countries. Oil price hikes have a negative impact on stock markets of oil dependent countries, while for oil exporters the impact is positive. Oil price falls hit negatively stock markets of oil dependent countries but stock market returns of oil exporters plunge even more.

Measures of asymmetry that account for oil instability or that are able to better extract the exogenous component of oil price changes indicate statistical significance only for oil price hikes. Although oil price declines have a strong impact in oil exporting countries, they are not so relevant when we account for volatility and endogeneity. This contrasts with the large magnitude of nopi as shown in Figure 4, but it is consistent with the fact that oil prices hikes being driven 
by exogenous shocks (Jones and Kaul, 1996) and that price declines might be only a correction of price hikes.

Second, oil price volatility has a negative impact on stock markets of oil dependent countries and positive on oil exporting countries, and the asymmetric effects persist with oil price volatility.

We find that some measures of volatility show volatility persistence, bi-directional relations and rise with oil futures price changes (whether positive or negative). The latter findings substantiate the theories of sectoral changes or uncertainty channels as causes of the existence of asymmetric effects between oil price changes and the economy (see Ferderer, 1996). We also find evidence of volatility feedback when we use the filtered volatility obtained from a $\operatorname{GARCH}(1,1)$ model.

The asymmetric effects found in the stock markets of oil exporting countries can be supported by the offset mechanism proposed by Ferderer (1996), because we find that, first, oil volatility has a positive effect on stock market returns and second, stock market returns follow oil price changes. This means that oil price falls increase oil price volatility, generating a positive effect on returns of stock markets, that offsets the negative effects generated by oil price declines. Overall, oil price declines tend to not affect the stock markets of oil exporting countries.

Moreover, the results are also consistent with the empirical evidence from oil exporting countries that shows that the economy has a positive response to oil price shocks (see Mork et al., 1994; Korhonen and Ledyaeva, 2010, for evidence for Norway and for Russia and Canada, respectively).

Understanding the impact of oil price fluctuations has become a prominent issue for investment decisions and consequently risk management. Our analysis makes a contribution to understanding the workings of oil price variations in stock markets. Considerable work remains to be done to validate the theories and mechanisms that explain the nonlinear effects of oil price changes. 


\section{References}

Abel, A. and B. Bernanke (2001). Macroeconomics. Addison Wesley.

Adler, M. and B. Dumas (1983). International portfolio selection and corporation finance: A synthesis. Journal of Finance 46, 925-984.

Aloui, C. and R. Jammazi (2009). The effects of crude oil shocks on stock market shifts behaviour: A regime switching approach. Energy Economics 31, 789-799.

Amira, K., A. Taamouti, and G. Tsafack (2009). What drives international equity correlations? volatility or market direction? Working Paper, Universidad Carlos III de Madrid.

Bachemeier, L. (2008). Monetary policy and the transmission of oil shocks. Journal of Macroeconomics 30, 1738-1755.

Bansal, R. and H. Zhou (2002). Term structure of interest rates with regime shifts. Journal of Finance 57, 1997-2043.

Barro, R. (1984). Macroeconomics. Wiley.

Basher, S. A. and P. Sadorsky (2006). Oil price risk and emerging stock markets. Global Finance Journal 17, 224-251.

Bekaert, G. and G. Wu (2000). Asymmetric volatility and risk in equity markets. The Review of Financial Studies 13, 1-42.

Bernanke, B. (1983). Irreversibility, uncertainty, and cyclical investment. The Quarterly Journal of Economics 98, 85-106.

BP-Statistics (2010). Review of World Energy.

Brown, S. and M. Yücel (1999). Oil prices and U.S. aggregate economic activity. Federal Reserve Bank of Dallas Economic Review, 16-53. 
Brown, S. and M. Yücel (2002). Energy prices and aggregate economic activity: An interpretative survey. The Quarterly Review of Economics and Finance 42(2), 193-208.

Carrieri, F. and B. Majerbi (2006). The pricing of exchange risk in emerging stock markets. Journal of International Business Studies 37, 372-391.

Chen, N.-F., R. Roll, and S. Ross (1986). Economic forces and the stock market. Journal of Business 59, 383-327.

Cobo-Reyes, R. and G. Quirós (2005). The effect of oil price on industrial production and on stock returns. WP 05/18, Universidad de Granada.

Cologni, A. and M. Manera (2008). Oil prices, inflation and interest rates in a structural cointegrated VAR model for the G-7 countries. Energy Economics 30, 856-888.

Cong, R.-G., Y.-M. Wei, J.-L. Jiao, and Y. Fan (2008). Relationships between oil price shocks and stock market: An empirical analysis from China. Energy Policy 36, 3544-3553.

Cuñado, J. and F. Garcia (2003). Do oil price shocks matter? Evidence for some European countries. Energy Economics 25, 137-154.

Davis, S. (1987). Allocative disturbances and specific capital in real business cycles theories. American Economic Review 7\%, 326-332.

De Santis, G. and B. Gerard (1998). How big is the premium for currency risk? Journal of Financial Economics 49, 375-412.

Dohner, R. (1981). Energy Prices, Inflation and Economic Activity, Chapter Energy prices, economic activity and inflation: Survey of issues and results. Ballinger.

Doran, J. and E. Ronn (2008). Computing the market price of volatility risk in the energy commodity markets. Journal of Banking and Finance 32, 2541-2552. 
Driesprong, G., B. Jacobsen, and B. Maat (2008). Striking Oil: Another Puzzle. Journal of Financial Economics 89, 307-327.

Dumas, B. and B. Solnik (1995). The world price of exchange rate risk. Journal of Finance 50, $445-477$.

Durham, G. (2003). Likelihood-based specification analysis of continuous-time models of the short-term interest rate. Journal of Financial Economics 70, 463-487.

Elder, J. and A. Serletis (2010). Oil price uncertainty. Journal of Money Credit and Banking 42, $1137-1159$.

Fama, E. (1990). Stock returns, expected returns, and real activity. Journal of Finance 45, $1089-1108$.

Ferderer, J. (1996). Oil price volatility and the macroeconomy: A solution to the asymmetry puzzle. Journal of Macroeconomics 18, 1-16.

Ferson, W. and C. Harvey (1994a). An exploratory investigation of the fundamental determinants of national equity market returns. In J. Frankel (Ed.), The Internationalization of Equity Markets. University of Chicago Press.

Ferson, W. and C. Harvey (1994b). Sources of risk and expected returns in global equity markets. Journal of Banking and Finance 18, 1625-1665.

Gallant, A. and G. Tauchen (1998). Reprojecting partially observed systems with application to interest rate diffusions. Journal of the American Statistical Association 93, 10-24.

Hamilton, J. (1988a). Are the macroeconomic effects of oil price changes symmetric? A comment. Cornegie-Rochester Conference Series on Public Policy 28, 369-378.

Hamilton, J. (1988b). A neoclassical model of unemployment and the business cycle. Journal of Political Economy 96, 593-617. 
Hamilton, J. (1996). This is what happened to the oil price-macroeconomy relationship. Journal of Monetary Economics 38, 215-220.

Huang, R., R. Masulis, and H. Stoll (1996). Energy shocks and financial markets. Journal of Futures Markets 16, 1-27.

Jones, C. and G. Kaul (1996). Oil and stock markets. Journal of Finance 51, 463-491.

Kilian, L. (2008). The economic effects of energy price shocks. Journal of Economic Literature 46, $871-909$.

Korhonen, I. and S. Ledyaeva (2010). Trade linkages and macoeconomic effects of the price of oil. Energy Economics 32, 848-856.

Lee, K., S. Ni, and R. Ratti (1995). Oil shocks and the macroeconomy: The role of price variability. The Energy Journal 16, 39-56.

Lilien, D. (1982). Sectoral shifts and cyclical unemployment. Journal of Political Economy 90, $777-794$.

Loungani, P. (1986). Oil prices shocks and the dispersion hypothesis. The Review of Economics and Statistics 68, 536-539.

Mork, K. (1989). Oil and the macroeconomy when prices go up and down: An extension of Hamilton's results. Journal of Political Economy 3, 740-744.

Mork, K. (1994). Business cycles and the oil market. The Energy Journal 15, 15-38.

Mork, K., O. Olsen, and H. Mysen (1994). Macroeconomic responses to oil price increases and decreases in seven OECD countries. The Energy Journal 15(4), 19-36.

Nandha, M. and R. Faff (2008). Does oil move equity prices? A global view. Energy Economics 30, 986-997. 
Park, J. and R. Ratti (2008). Oil price shocks and stock markets in the U.S. and 13 European countries. Energy Economics 30, 2587-2608.

Pierce, J. and J. Enzler (1974). The effects of external inflationary shocks. Brookings Papers on Economic Activity 1, 13-61.

Ramos, S. and H. Veiga (2010). Risk factors in oil and gas industry returns: international evidence. Energy Economics, forthcoming.

Rasche, R. and J. Tatom (1981). Energy price shocks, aggregate supply and monetary policy: The theory and international evidence. Journal of Monetary Economics 14, 9-93.

Sadorsky, P. (1999). Oil price shocks and stock market activity. Energy Economics 21, 449-469.

Sadorsky, P. (2008). Assessing the impact of oil prices on firms of different sizes: It's tough being in the middle. Energy Policy 36, 3854-3861.

Sajjadur, R. and A. Serletis (2010). The asymmetric effects of oil price and monetary policy shocks: A nonlinear VAR approach. Energy Economics 32, 1460-1466.

Schwert, G. (1989). Why does stock market volatility change over time? Journal of Finance 44 , $1115-1153$.

Schwert, G. (1990). Stock returns and real activity: A century of evidence. Journal of Finance 45, $1237-1257$.

Solnik, B. (1974). The international pricing of risk: An empirical investigation of the world capital market structure. Journal of Finance 29, 365-378.

Stulz, R. (1981). A model of international asset pricing. Journal of Financial Economics 9, 383-406.

Tatom, J. (1988). Are the macroeconomic effects of oil price changes symmetric? In K. Brunner and A. Meltzer (Eds.), Stabilization Policies and Labor Markets. North-Holland. 


\section{Tables and Figures}
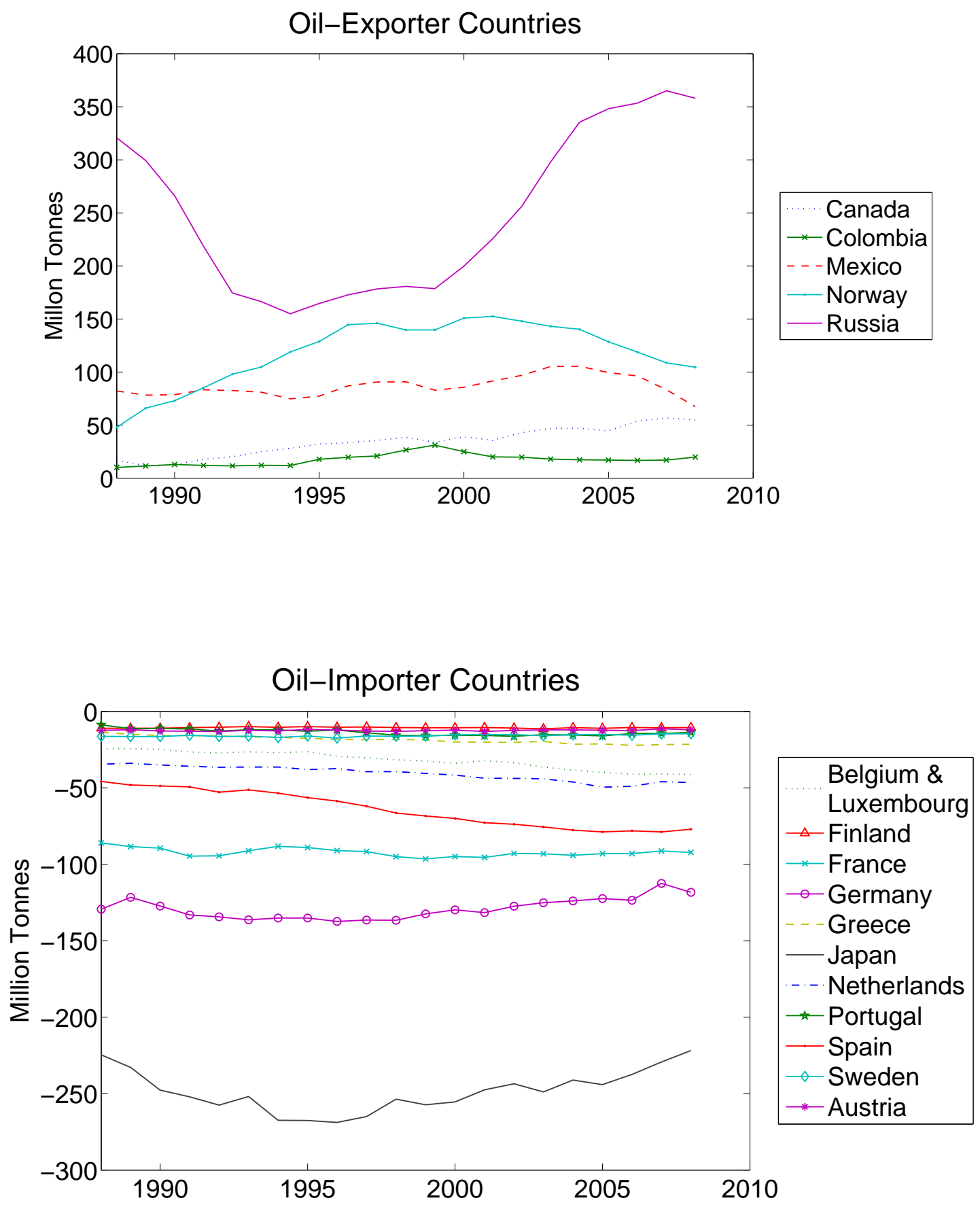

Figure 1. Net oil production. A negative net production means that the country is a net importer of oil and vice-versa. Data source: BP-Statistics (2010). 

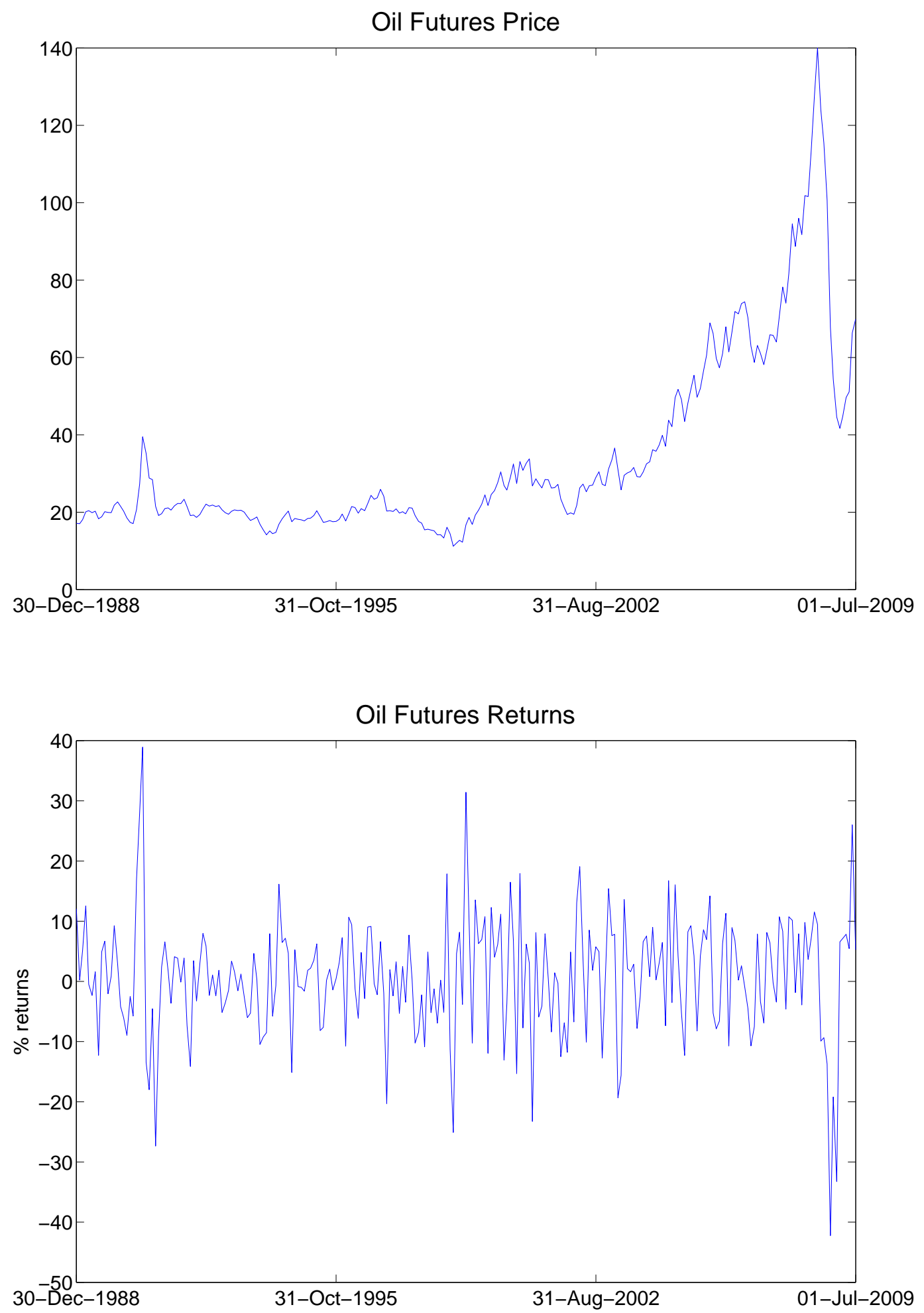

Figure 2. Oil futures price (first panel) and oil futures returns in percentage (second panel). 

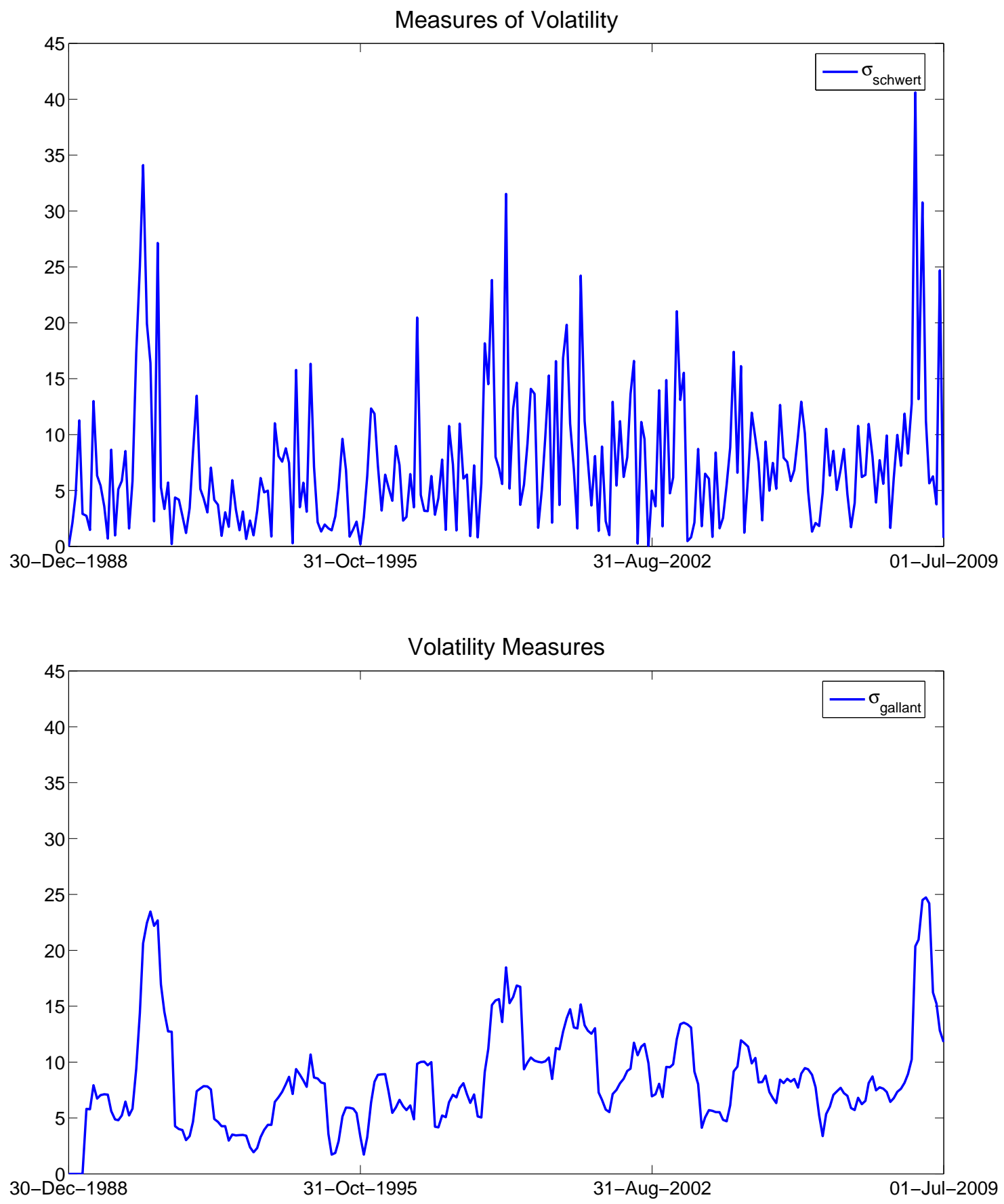

Figure 3. Oil price volatility measures. 

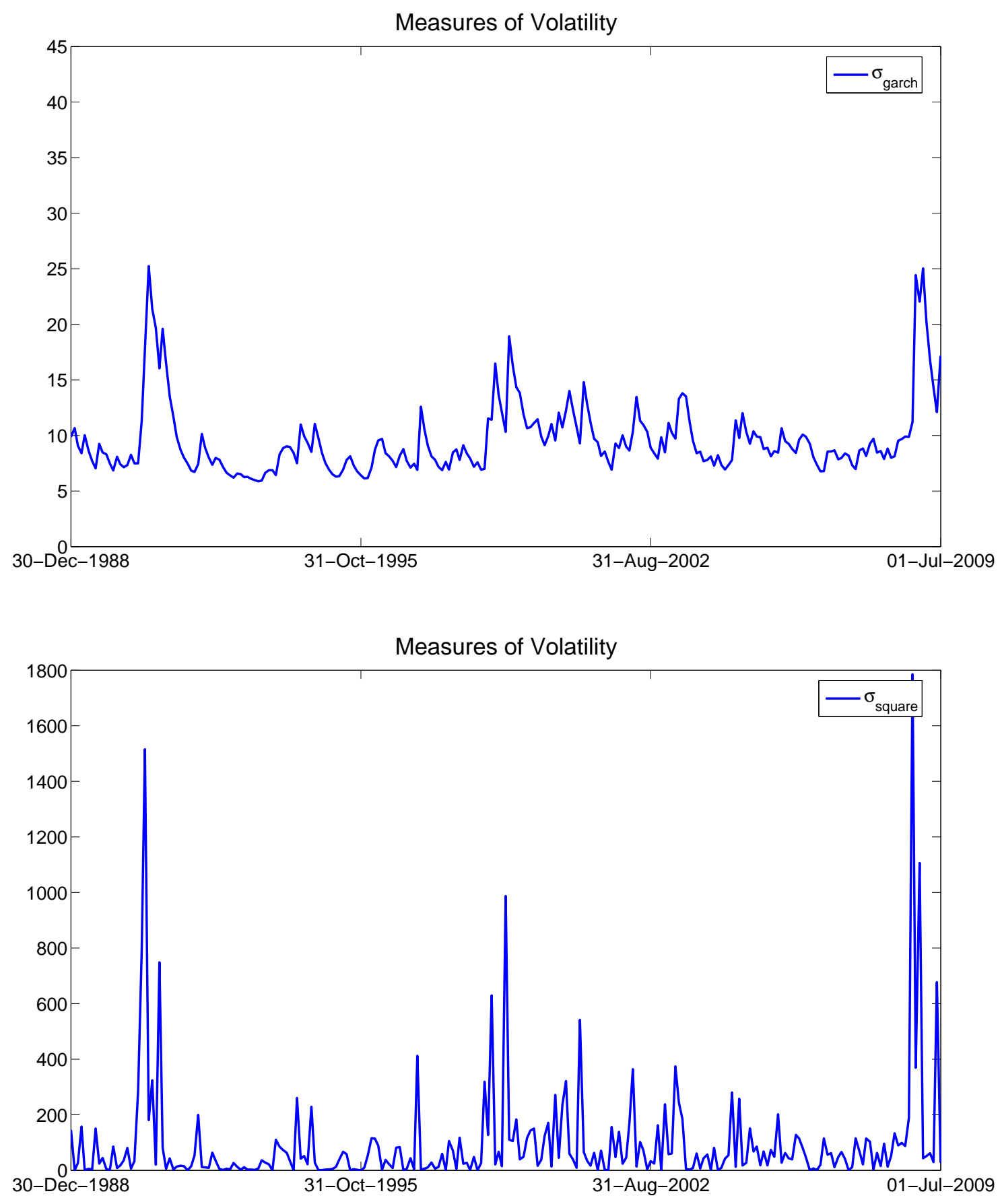

Figure 3. Oil price volatility measures (cont.). 


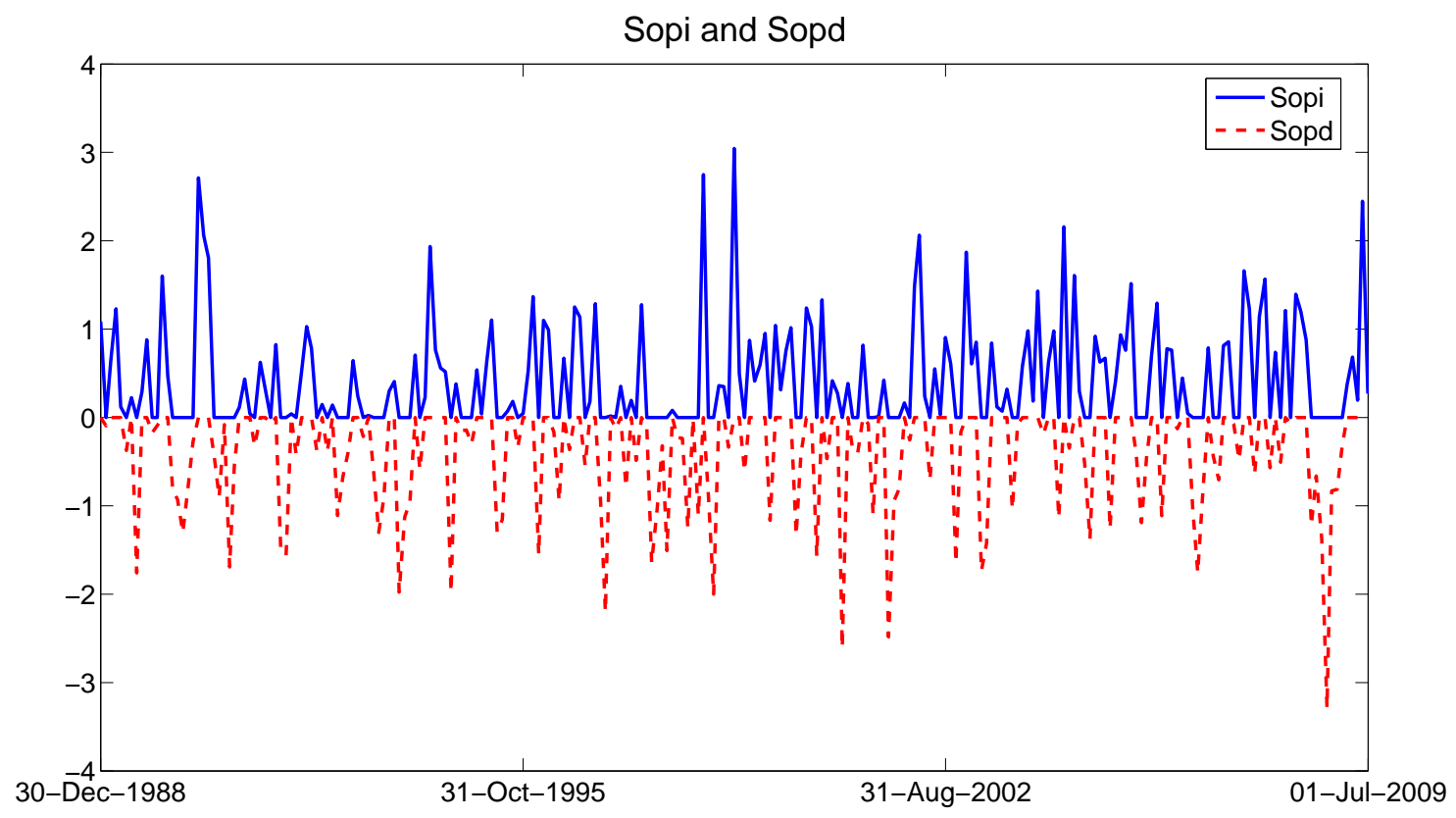

Figure 4. Scaled oil futures price increases (continuous blue line) and scale oil futures price decreases (dotted red line).

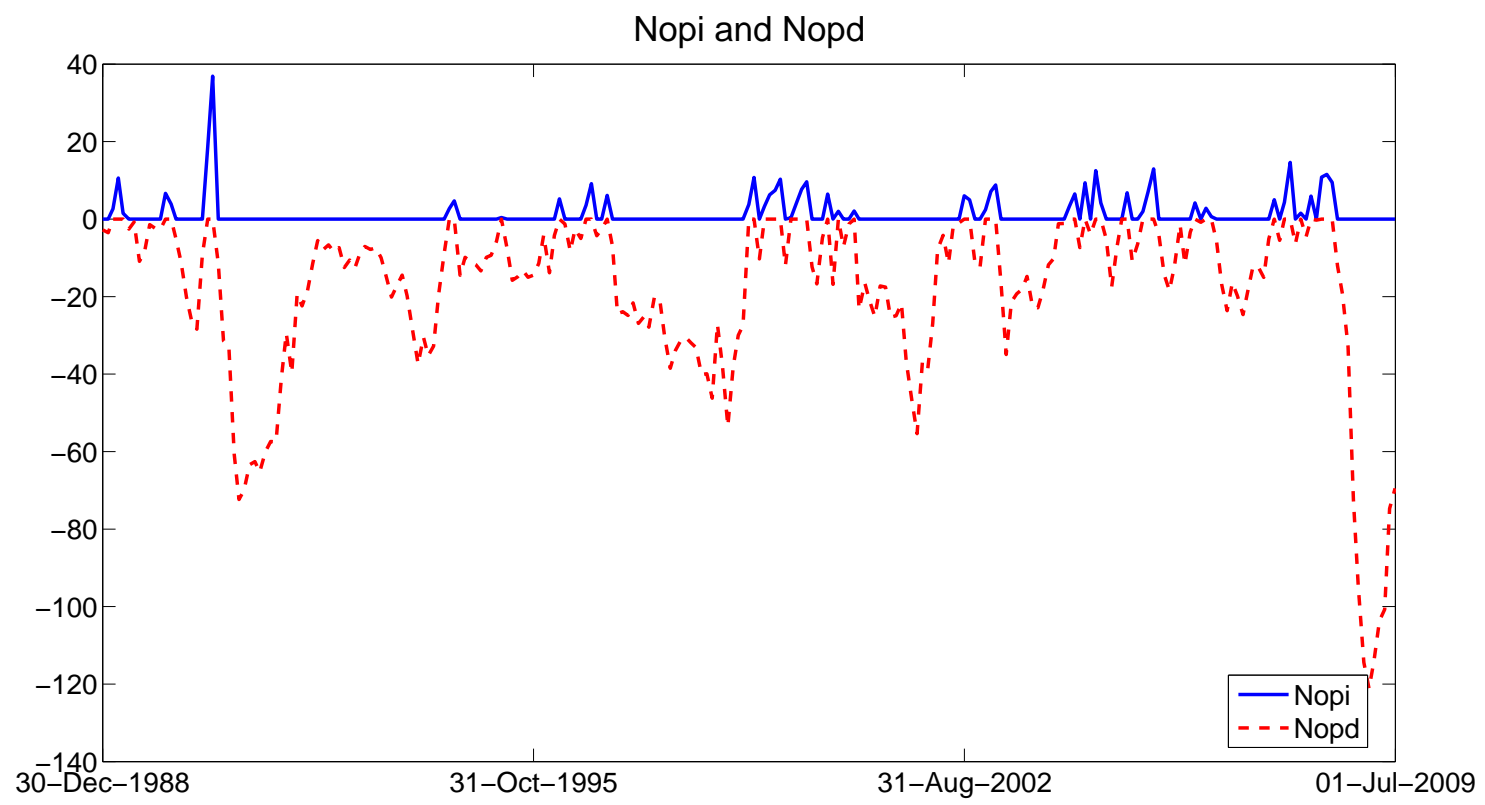

Figure 5. Net oil futures price increases (continuous blue line) and net oil price declines (dotted red line). 
Table I

Summary Statistics of Variables

This table reports the summary statistics of the variables. Panels A.1 and A.2 report stock market indexes monthly returns by country. Panel B reports the same statistics for the variables oil, world, currency and volatility measures $\left(\hat{\sigma}_{\text {schwert }}, \hat{\sigma}_{\text {gallant }}, \hat{\sigma}_{\text {garch }}, \hat{\sigma}_{\text {square }}\right)$. The sample period ranges from 1988:12 to 2009:06. By column, we report the mean, the standard deviation (SD), the kurtosis, the skewness and the Jarque-Bera test statistics. The returns are the first differences of the logarithm of prices in percentage. Superscripts $*, * *$ and $* * *$ denote statistical significance at $10 \%, 5 \%$ and $1 \%$ levels respectively. Source: Datastream.

\begin{tabular}{lrrrrr}
\hline \multicolumn{5}{c}{ Panel A.1: Oil-Dependent Countries } \\
\hline COUNTRY & Mean & SD & Kurtosis & Skewness & Jarque-Bera \\
\hline Austria & 0.214 & 7.110 & 11.098 & -1.491 & $750.525^{* * *}$ \\
Belgium & -0.043 & 5.697 & 14.073 & -1.908 & $1384.900^{* * *}$ \\
Finland & 0.135 & 8.778 & 3.968 & -0.247 & $11.491^{* * *}$ \\
France & 0.126 & 5.637 & 4.937 & -0.793 & $62.617^{* * *}$ \\
Germany & 0.093 & 5.985 & 5.204 & -0.876 & $79.335^{* * *}$ \\
Greece & 0.466 & 10.002 & 7.718 & 0.650 & $240.315^{* * *}$ \\
Ireland & 0.046 & 6.363 & 7.865 & -1.064 & $283.564^{* * *}$ \\
Japan & -0.604 & 6.476 & 3.727 & 0.153 & $5.973^{*}$ \\
Netherlands & 0.085 & 5.793 & 14.051 & -2.192 & $1427.300^{* * *}$ \\
Portugal & -0.124 & 6.100 & 6.588 & -0.885 & $150.986^{* * *}$ \\
Spain & 0.111 & 6.230 & 5.095 & -0.675 & $61.966^{* * *}$ \\
Sweden & 0.156 & 7.515 & 4.425 & -0.635 & $36.287^{* * *}$ \\
Switzerland & 0.344 & 4.919 & 4.253 & -0.528 & $26.639^{* * *}$ \\
\hline \multicolumn{5}{c}{ Panel A.2: Oil-Exporter Countries } \\
\hline COUNTRY & Mean & SD & Kurtosis & Skewness & Jarque-Bera \\
\hline Canada & 0.251 & 5.486 & 8.198 & -1.171 & $326.795^{* * *}$ \\
Colombia & -0.579 & 3.102 & 4.893 & -0.405 & $35.340^{* * *}$ \\
Mexico & 0.685 & 9.287 & 6.781 & -1.239 & $205.320^{* * *}$ \\
Norway & 0.350 & 7.725 & 8.209 & -1.348 & $345.906^{* * *}$ \\
Russia & 1.381 & 14.522 & 5.674 & -0.966 & $78.672^{* * *}$ \\
\hline
\end{tabular}


Table I

Summary Statistics of Variables (cont.)

\begin{tabular}{|c|c|c|c|c|c|}
\hline & \multicolumn{5}{|c|}{ Panel B: Independent Variables } \\
\hline & Mean & SD & Kurtosis & Skewness & Jarque-Bera \\
\hline oil (NYMEX) & 0.618 & 9.852 & 5.425 & -0.277 & $61.492^{* * *}$ \\
\hline \multirow[t]{3}{*}{ world } & -0.052 & 4.639 & 6.026 & -0.965 & $129.149^{* * *}$ \\
\hline & \multicolumn{5}{|c|}{ Panel B.1: Currency Oil-Dependent Countries } \\
\hline & Mean & SD & Kurtosis & Skewness & Jarque-Bera \\
\hline Austria & 0.087 & 3.062 & 4.283 & -0.354 & $21.129^{* * *}$ \\
\hline Belgium & 0.094 & 3.046 & 4.319 & -0.386 & $23.035^{* * *}$ \\
\hline Finland & -0.016 & 3.235 & 4.700 & -0.506 & $38.900^{* * *}$ \\
\hline France & 0.095 & 3.021 & 4.311 & -0.365 & $22.169^{* * *}$ \\
\hline Germany & 0.106 & 3.053 & 4.423 & -0.311 & $22.574^{* * *}$ \\
\hline Greece & -0.212 & 3.052 & 4.822 & -0.474 & $41.806^{* * *}$ \\
\hline Ireland & 0.055 & 3.071 & 4.486 & -0.469 & $30.496^{* * *}$ \\
\hline Japan & 0.094 & 3.151 & 5.898 & 0.452 & $91.876^{* * *}$ \\
\hline Netherlands & 0.089 & 3.060 & 4.264 & -0.334 & $20.140^{* * *}$ \\
\hline Portugal & 0.003 & 3.056 & 4.471 & -0.337 & $25.815^{* * *}$ \\
\hline Spain & -0.021 & 3.194 & 4.549 & -0.539 & $35.358^{* * *}$ \\
\hline Sweden & -0.101 & 3.341 & 4.908 & -0.680 & $54.678^{* * *}$ \\
\hline \multirow[t]{3}{*}{ Switzerland } & 0.117 & 3.240 & 4.038 & -0.039 & $10.400^{* * *}$ \\
\hline & \multicolumn{5}{|c|}{ Panel B.2: Currency Oil-Exporter Countries } \\
\hline & Mean & SD & Kurtosis & Skewness & Jarque-Bera \\
\hline Canada & 0.009 & 2.055 & 9.018 & -0.505 & $373.740^{* * *}$ \\
\hline Colombia & -0.579 & 3.102 & 4.893 & -0.405 & $35.340^{* * *}$ \\
\hline Mexico & -0.705 & 3.813 & 39.825 & -4.568 & $14555.000^{* * *}$ \\
\hline Norway & 0.002 & 3.056 & 4.514 & -0.568 & $35.589^{* * *}$ \\
\hline \multirow[t]{3}{*}{ Russia } & -0.106 & 2.581 & 35.281 & -4.253 & $4584.200^{* * *}$ \\
\hline & \multicolumn{5}{|c|}{ Panel B.3: Volatility Measures } \\
\hline & Mean & SD & Kurtosis & Skewness & Jarque-Bera \\
\hline$\hat{\sigma}_{\text {schwert }}$ & 7.399 & 6.325 & 8.109 & 1.909 & $408.275^{* * *}$ \\
\hline$\hat{\sigma}_{\text {gallant }}$ & 8.660 & 4.404 & 5.444 & 1.416 & $137.903^{* * *}$ \\
\hline$\hat{\sigma}_{\text {garch }}$ & 9.597 & 3.309 & 9.413 & 2.307 & $629.856^{* * *}$ \\
\hline$\hat{\sigma}_{\text {square }}$ & 97.442 & 203.354 & 34.627 & 5.094 & $11169.000^{* * *}$ \\
\hline
\end{tabular}


Table II

\section{Correlations-Independent Variables}

This table reports the correlation among independent variables. Explanatory variables are world market returns (world), oil futures returns (oil), currency variations against the U.S. dollar (currency) and four oil volatility measures $\left(\hat{\sigma}_{\text {schwert }}, \hat{\sigma}_{\text {gallant }}, \hat{\sigma}_{\text {garch }}, \hat{\sigma}_{\text {square }}\right)$. The sample period runs from 1988:12 through 2009:06.

\begin{tabular}{lrrrrrrr}
\hline & world & oil & currency & $\hat{\sigma}_{\text {schwert }}$ & $\hat{\sigma}_{\text {gallant }}$ & $\hat{\sigma}_{\text {garch }}$ & $\hat{\sigma}_{\text {square }}$ \\
\hline world & 1.000 & & & & & & \\
oil & 0.0920 & 1.0000 & & & & & \\
currency & 0.2665 & 0.1424 & 1.0000 & & & & \\
$\hat{\sigma}_{\text {schwert }}$ & -0.0539 & -0.1032 & 0.0593 & 1.0000 & & & \\
$\hat{\sigma}_{\text {gallant }}$ & -0.0719 & -0.0730 & -0.0421 & 0.5546 & 1.0000 & & \\
$\hat{\sigma}_{\text {garch }}$ & -0.0213 & -0.0550 & -0.0678 & 0.2958 & 0.8902 & 1.0000 & \\
$\hat{\sigma}_{\text {square }}$ & -0.1825 & -0.0750 & 0.0235 & 0.8755 & 0.5297 & 0.2952 & 1.0000 \\
\hline
\end{tabular}


Table III

\section{Stock market returns and oil price changes}

This table reports fixed effects panel regression estimations with interactions (Equations (1), (2) and (3)) from 1988:12 through 2009:06. The dependent variable is the monthly excess returns of stock market indexes in U.S. dollars. Explanatory variables include the world market return (world), currency variations against the U.S. dollar (currency), positive variations of oil price returns (oilp), negative variations of oil price returns (oiln), scaled oil price increases (sopi) and scaled oil price declines (sopd), net oil price increases (nopi) and net oil price declines (nopd). export is a dummy variable that assumes value of one when the country is an oil exporter country and zero otherwise. Oil price variations are computed using oil futures prices. Standard errors are clustered by country and are robust to heteroscedasticity. p-values are reported below coefficients.

\begin{tabular}{|c|c|c|c|}
\hline & (1) & (2) & (3) \\
\hline \multirow[t]{2}{*}{ world } & 0.922 & 0.927 & 0.925 \\
\hline & $(0.000)$ & $(0.000)$ & $(0.000)$ \\
\hline \multirow[t]{2}{*}{ currency } & 0.550 & 0.560 & 0.551 \\
\hline & $(0.000)$ & $(0.000)$ & $(0.000)$ \\
\hline \multirow[t]{2}{*}{ oilp } & -0.092 & & \\
\hline & $(0.000)$ & & \\
\hline \multirow[t]{2}{*}{ oiln } & 0.039 & & \\
\hline & $(0.022)$ & & \\
\hline \multirow[t]{2}{*}{ oilp·export } & 0.174 & & \\
\hline & $(0.000)$ & & \\
\hline \multirow{2}{*}{ oiln.export } & 0.104 & & \\
\hline & $(0.057)$ & & \\
\hline \multirow[t]{2}{*}{ sopi } & & -0.895 & \\
\hline & & $(0.000)$ & \\
\hline \multirow[t]{2}{*}{ sopd } & & 0.302 & \\
\hline & & $(0.091)$ & \\
\hline \multirow[t]{2}{*}{ sopi·export } & & 1.673 & \\
\hline & & $(0.000)$ & \\
\hline \multirow[t]{2}{*}{ sopd·export } & & 0.675 & \\
\hline & & $(0.231)$ & \\
\hline \multirow[t]{2}{*}{ nopi } & & & -0.111 \\
\hline & & & $(0.000)$ \\
\hline \multirow[t]{2}{*}{ nopd } & & & 0.007 \\
\hline & & & $(0.054)$ \\
\hline \multirow[t]{2}{*}{ nopi-export } & & & 0.211 \\
\hline & & & $(0.001)$ \\
\hline \multirow[t]{2}{*}{ nopd·export } & & & 0.000 \\
\hline & & & $(0.990)$ \\
\hline \multirow[t]{2}{*}{ Constant } & 0.635 & 0.636 & 0.460 \\
\hline & $(0.000)$ & $(0.000)$ & $(0.000)$ \\
\hline Observations & 4238 & 4238 & 4238 \\
\hline Countries & 18 & 18 & 18 \\
\hline$R^{2}$ & 0.514 & 0.511 & 0.507 \\
\hline Test 1 & 42.560 & 23.640 & 25.260 \\
\hline P-value & $(0.000)$ & $(0.000)$ & $(0.000)$ \\
\hline Test 2 & 28.250 & 18.300 & 12.680 \\
\hline P-value & $(0.000)$ & $(0.000)$ & $(0.000)$ \\
\hline
\end{tabular}




\section{Table IV \\ Stock market returns and oil price volatility}

This table reports fixed effects panel regression estimations with interactions (Equations (1), (2) and (3)) from 1988:12 through 2009:06. The dependent variable is the monthly excess returns of stock market indexes in U.S. dollars. Explanatory variables include the world market return (world), positive variations of oil price returns (oilp), negative variations of oil price returns (oiln), currency variations against the U.S. dollar (currency), net oil price increases (nopi) and net oil price declines (nopd) and volatility of oil futures price $\left(\hat{\sigma}_{\text {schwert }}, \hat{\sigma}_{\text {gallant }}, \hat{\sigma}_{\text {garch }}\right.$, $\left.\hat{\sigma}_{\text {square }}\right)$. export is a dummy variable that assumes value of one when the country is an oil-exporter country and zero otherwise. Oil price variations are computed using oil futures prices. Standard errors are clustered by country and are robust to heteroscedasticity. p-values are reported below coefficients.

\begin{tabular}{|c|c|c|c|c|c|c|c|c|}
\hline & (1) & $(2)$ & (3) & (4) & $(5)$ & (6) & $(7)$ & $(8)$ \\
\hline \multirow[t]{2}{*}{ world } & 0.921 & 0.921 & 0.923 & 0.910 & 0.922 & 0.922 & 0.926 & 0.909 \\
\hline & $(0.000)$ & $(0.000)$ & $(0.000)$ & $(0.000)$ & $(0.000)$ & $(0.000)$ & $(0.000)$ & $(0.000)$ \\
\hline \multirow[t]{2}{*}{ currency } & 0.554 & 0.557 & 0.548 & 0.557 & 0.562 & 0.559 & 0.550 & 0.562 \\
\hline & $(0.000)$ & $(0.000)$ & $(0.000)$ & $(0.000)$ & $(0.000)$ & $(0.000)$ & $(0.000)$ & $(0.000)$ \\
\hline \multirow[t]{2}{*}{ oilp } & -0.059 & -0.087 & -0.086 & -0.043 & & & & \\
\hline & $(0.012)$ & $(0.000)$ & $(0.000)$ & $(0.076)$ & & & & \\
\hline \multirow[t]{2}{*}{ oiln } & 0.001 & 0.027 & 0.032 & -0.013 & & & & \\
\hline & $(0.943)$ & $(0.080)$ & $(0.057)$ & $(0.443)$ & & & & \\
\hline \multirow[t]{2}{*}{ oilp.export } & 0.113 & 0.154 & 0.159 & 0.141 & & & & \\
\hline & $(0.017)$ & $(0.000)$ & $(0.000)$ & $(0.022)$ & & & & \\
\hline \multirow[t]{2}{*}{ oiln·export } & 0.172 & 0.128 & 0.121 & 0.138 & & & & \\
\hline & $(0.003)$ & $(0.024)$ & $(0.025)$ & $(0.018)$ & & & & \\
\hline \multirow[t]{2}{*}{ nopi } & & & & & -0.077 & -0.099 & -0.095 & -0.056 \\
\hline & & & & & $(0.001)$ & $(0.001)$ & $(0.002)$ & $(0.010)$ \\
\hline \multirow[t]{2}{*}{ nopd } & & & & & 0.002 & 0.000 & 0.001 & -0.001 \\
\hline & & & & & $(0.616)$ & $(0.968)$ & $(0.815)$ & $(0.811)$ \\
\hline \multirow[t]{2}{*}{ nopi·export } & & & & & 0.201 & 0.197 & 0.172 & 0.214 \\
\hline & & & & & $(0.004)$ & $(0.002)$ & $(0.011)$ & $(0.004)$ \\
\hline \multirow[t]{2}{*}{ nopd·export } & & & & & 0.001 & 0.006 & 0.014 & -0.002 \\
\hline & & & & & $(0.899)$ & $(0.415)$ & $(0.109)$ & $(0.788)$ \\
\hline \multirow[t]{2}{*}{$\hat{\sigma}_{\text {schwert }}$} & -0.050 & & & & -0.062 & & & \\
\hline & $(0.042)$ & & & & $(0.000)$ & & & \\
\hline \multirow[t]{2}{*}{$\hat{\sigma}_{\text {schwert }} \cdot \operatorname{export}$} & 0.092 & & & & 0.012 & & & \\
\hline & $(0.005)$ & & & & $(0.682)$ & & & \\
\hline \multirow[t]{2}{*}{$\hat{\sigma}_{\text {gallant }}$} & & -0.034 & & & & -0.061 & & \\
\hline & & $(0.061)$ & & & & $(0.020)$ & & \\
\hline \multirow[t]{2}{*}{$\hat{\sigma}_{\text {gallant }} \cdot$ export } & & 0.087 & & & & 0.062 & & \\
\hline & & $(0.005)$ & & & & $(0.048)$ & & \\
\hline \multirow[t]{2}{*}{$\hat{\sigma}_{\text {garch }}$} & & & -0.050 & & & & -0.065 & \\
\hline & & & $(0.069)$ & & & & $(0.112)$ & \\
\hline \multirow[t]{2}{*}{$\hat{\sigma}_{\text {garch }} \cdot$ export } & & & 0.136 & & & & 0.161 & \\
\hline & & & $(0.023)$ & & & & $(0.036)$ & \\
\hline \multirow[t]{2}{*}{$\hat{\sigma}_{\text {square }}$} & & & & -0.002 & & & & -0.002 \\
\hline & & & & $(0.037)$ & & & & $(0.004)$ \\
\hline \multirow[t]{2}{*}{$\hat{\sigma}_{\text {square }} \cdot \operatorname{export}$} & & & & 0.002 & & & & 0.000 \\
\hline & & & & $(0.406)$ & & & & $(0.743)$ \\
\hline \multirow[t]{2}{*}{ Constant } & 0.707 & 0.703 & 0.779 & 0.543 & 0.765 & 0.725 & 0.655 & 0.476 \\
\hline & $(0.000)$ & $(0.000)$ & $(0.003)$ & $(0.000)$ & $(0.000)$ & $(0.000)$ & $(0.018)$ & $(0.000)$ \\
\hline Observations & 4224 & 4168 & 4238 & 4238 & 4224 & 4168 & 4238 & 4238 \\
\hline Countries & 18 & 18 & 18 & 18 & 18 & 18 & 18 & 18 \\
\hline$R^{2}$ & 0.516 & 0.518 & 0.515 & 0.516 & 0.51 & 0.512 & 0.508 & 0.511 \\
\hline Test 1 & 2.960 & 46.430 & 37.780 & 0.720 & 13.620 & 14.560 & 10.990 & 7.050 \\
\hline $\mathrm{P}$-value & $(0.104)$ & $(0.000)$ & $(0.000)$ & $(0.408)$ & $(0.002)$ & $(0.001)$ & $(0.004)$ & $(0.017)$ \\
\hline Test 2 & 5.140 & 34.490 & 28.100 & 4.050 & 7.680 & 11.310 & 9.650 & 5.070 \\
\hline $\mathrm{P}$-value & $(0.018)$ & $(0.000)$ & $(0.000)$ & $(0.036)$ & $(0.004)$ & $(0.001)$ & $(0.002)$ & $(0.002)$ \\
\hline
\end{tabular}


Table V

Asymmetric effects of oil price fluctuations in sectors

This table reports fixed effects panel regression estimations with interactions. Panel A- Equation (1), Panel B: Equation (2) and Panel C: Equation (3)). Data is from 1988:12 through 2009:06. The dependent variable is the monthly excess returns of the several sector stock market indexes in U.S. dollars. Explanatory variables include the world market return (world), positive variations of oil price returns (oilp), negative variations of oil price returns (oiln), currency variations against the U.S. dollar (currency), net oil price increases (nopi) and net oil price declines (nopd). export is a dummy variable that assumes value of one when the country is an oil exporter country and zero otherwise. Oil price variations are computed using oil futures prices. Standard errors are clustered by country and are robust to heteroscedasticity. p-values are reported below coefficients.

\begin{tabular}{|c|c|c|c|c|c|c|c|}
\hline \multirow{2}{*}{ sectors } & \multicolumn{7}{|c|}{ Panel A: Measures of asymmetry oilp and oiln } \\
\hline & oilp & oiln & oilp·export & oiln.export & $R^{2}$ & Obs & Countries \\
\hline \multirow[t]{2}{*}{ basicmat } & -0.058 & 0.073 & 0.122 & 0.080 & 0.376 & 4238 & 18 \\
\hline & $(0.005)$ & $(0.014)$ & $(0.037)$ & $(0.293)$ & & & \\
\hline \multirow[t]{2}{*}{ consgood } & -0.096 & 0.072 & 0.075 & -0.005 & 0.197 & 3950 & 18 \\
\hline & $(0.000)$ & (0.010) & $(0.029)$ & $(0.919)$ & & & \\
\hline \multirow[t]{2}{*}{ consserv } & -0.097 & 0.014 & 0.130 & 0.042 & 0.288 & 4238 & 18 \\
\hline & $(0.000)$ & $(0.335)$ & $(0.006)$ & $(0.550)$ & & & \\
\hline \multirow{2}{*}{ financials } & -0.095 & 0.044 & 0.110 & 0.032 & 0.379 & 4105 & 18 \\
\hline & $(0.000)$ & $(0.110)$ & $(0.017)$ & $(0.650)$ & & & \\
\hline \multirow[t]{2}{*}{ healthcare } & -0.039 & 0.033 & 0.075 & 0.067 & 0.183 & 3560 & 18 \\
\hline & $(0.010)$ & $(0.381)$ & $(0.053)$ & $(0.636)$ & & & \\
\hline \multirow[t]{2}{*}{ industrials } & -0.075 & 0.064 & -0.016 & 0.081 & 0.291 & 4017 & 18 \\
\hline & $(0.002)$ & (0.008) & $(0.881)$ & $(0.355)$ & & & \\
\hline \multirow[t]{2}{*}{ oilgas } & 0.117 & 0.230 & 0.202 & -0.036 & 0.296 & 2861 & 17 \\
\hline & $(0.018)$ & $(0.000)$ & $(0.005)$ & $(0.629)$ & & & \\
\hline \multirow[t]{2}{*}{ technology } & -0.117 & 0.039 & -0.003 & 0.070 & 0.282 & 3113 & 15 \\
\hline & $(0.007)$ & $(0.382)$ & $(0.966)$ & $(0.366)$ & & & \\
\hline \multirow[t]{2}{*}{ telecom } & -0.115 & -0.067 & 0.063 & 0.164 & 0.26 & 2973 & 18 \\
\hline & $(0.002)$ & $(0.108)$ & $(0.114)$ & $(0.021)$ & & & \\
\hline \multirow[t]{4}{*}{ utilities } & -0.045 & 0.019 & 0.001 & 0.031 & 0.293 & 3328 & 17 \\
\hline & $(0.074)$ & $(0.524)$ & $(0.980)$ & $(0.547)$ & & & \\
\hline & & Panel I & Measures & of asymmet & sopi & nd $s \mathrm{sl}_{1}$ & \\
\hline & sopi & sopd & sopi $\cdot$ export & sopd-export & $R^{2}$ & Obs & Countries \\
\hline \multirow[t]{2}{*}{ basicmat } & -0.648 & 0.685 & 1.233 & 0.772 & 0.375 & 4238 & 18 \\
\hline & $(0.004)$ & $(0.008)$ & $(0.063)$ & $(0.310)$ & & & \\
\hline \multirow[t]{2}{*}{ consgood } & -1.287 & 1.157 & 0.542 & -0.401 & 0.198 & 3950 & 18 \\
\hline & $(0.000)$ & (0.002) & $(0.485)$ & $(0.694)$ & & & \\
\hline \multirow[t]{2}{*}{ consserv } & -1.202 & 0.597 & 1.845 & -0.353 & 0.289 & 4238 & 18 \\
\hline & $(0.000)$ & (0.003) & $(0.000)$ & $(0.579)$ & & & \\
\hline \multirow[t]{2}{*}{ financials } & -1.122 & 0.003 & 1.359 & 0.397 & 0.38 & 4105 & 18 \\
\hline & $(0.000)$ & $(0.991)$ & (0.021) & $(0.520)$ & & & \\
\hline \multirow[t]{2}{*}{ healthcare } & -0.192 & 0.020 & 1.091 & 0.521 & 0.183 & 3560 & 18 \\
\hline & $(0.183)$ & $(0.956)$ & $(0.070)$ & $(0.743)$ & & & \\
\hline \multirow[t]{2}{*}{ industrials } & -0.879 & 0.631 & -0.141 & 0.169 & 0.29 & 4017 & 18 \\
\hline & $(0.000)$ & $(0.017)$ & $(0.867)$ & $(0.844)$ & & & \\
\hline \multirow[t]{2}{*}{ oilgas } & 0.800 & 2.312 & 1.527 & -0.272 & 0.286 & 2861 & 17 \\
\hline & $(0.191)$ & $(0.001)$ & $(0.208)$ & $(0.701)$ & & & \\
\hline \multirow[t]{2}{*}{ technology } & -1.289 & 0.779 & -0.732 & 0.056 & 0.283 & 3113 & 15 \\
\hline & $(0.002)$ & $(0.169)$ & $(0.304)$ & $(0.959)$ & & & \\
\hline \multirow[t]{2}{*}{ telecom } & -1.545 & -0.458 & 1.443 & 1.033 & 0.262 & 2973 & 18 \\
\hline & $(0.000)$ & $(0.315)$ & $(0.008)$ & $(0.103)$ & & & \\
\hline \multirow[t]{2}{*}{ utilities } & -0.217 & -0.120 & 0.106 & 0.224 & 0.292 & 3328 & 17 \\
\hline & $(0.281)$ & $(0.587)$ & $(0.767)$ & $(0.667)$ & & & \\
\hline
\end{tabular}




\section{Table V}

\section{Asymmetric effects of oil price fluctuations in sectors (cont.)}

This table reports fixed effects panel regression estimations with interactions. Panel A- Equation (1), Panel B: Equation (2) and Panel C: Equation (3)). Data is from 1988:12 through 2009:06. The dependent variable is the monthly excess returns of the several sector stock market indexes in U.S. dollars. Explanatory variables include the world market return (world), positive variations of oil price returns (oilp), negative variations of oil price returns (oiln), currency variations against the U.S. dollar (currency), net oil price increases (nopi) and net oil price declines (nopd). export is a dummy variable that assumes value of one when the country is an oil exporter country and zero otherwise. Oil price variations are computed using oil futures prices. Standard errors are clustered by country and are robust to heteroscedasticity. p-values are reported below coefficients.

\begin{tabular}{|c|c|c|c|c|c|c|c|}
\hline & \multicolumn{7}{|c|}{ Panel C: Measures of asymmetry nopi and nopd } \\
\hline sectors & nopi & nopd & nopi·export & nopd·export & $R^{2}$ & Obs & Countries \\
\hline \multirow[t]{2}{*}{ basicmat } & -0.100 & 0.012 & 0.228 & -0.012 & 0.372 & 4238 & 18 \\
\hline & $(0.008)$ & $(0.025)$ & $(0.001)$ & $(0.180)$ & & & \\
\hline \multirow[t]{2}{*}{ consgood } & -0.184 & 0.005 & 0.150 & -0.017 & 0.197 & 3950 & 18 \\
\hline & $(0.000)$ & $(0.470)$ & $(0.039)$ & $(0.427)$ & & & \\
\hline \multirow[t]{2}{*}{ consserv } & -0.136 & -0.013 & 0.145 & 0.017 & 0.289 & 4238 & 18 \\
\hline & $(0.006)$ & $(0.047)$ & $(0.071)$ & (0.197) & & & \\
\hline \multirow[t]{2}{*}{ financials } & -0.150 & 0.014 & 0.106 & 0.003 & 0.379 & 4105 & 18 \\
\hline & $(0.000)$ & $(0.053)$ & $(0.044)$ & $(0.794)$ & & & \\
\hline \multirow[t]{2}{*}{ healthcare } & -0.155 & 0.014 & 0.225 & -0.019 & 0.185 & 3560 & 18 \\
\hline & $(0.001)$ & $(0.061)$ & $(0.057)$ & $(0.221)$ & & & \\
\hline \multirow[t]{2}{*}{ industrials } & -0.032 & -0.002 & -0.043 & 0.013 & 0.287 & 4017 & 18 \\
\hline & $(0.392)$ & $(0.832)$ & $(0.600)$ & $(0.325)$ & & & \\
\hline \multirow[t]{2}{*}{ oilgas } & 0.092 & 0.018 & 0.206 & 0.012 & 0.262 & 2861 & 17 \\
\hline & $(0.272)$ & $(0.012)$ & $(0.065)$ & $(0.286)$ & & & \\
\hline \multirow[t]{2}{*}{ technology } & 0.072 & -0.019 & 0.114 & -0.028 & 0.282 & 3113 & 15 \\
\hline & $(0.414)$ & $(0.007)$ & $(0.562)$ & $(0.071)$ & & & \\
\hline \multirow[t]{2}{*}{ telecom } & -0.008 & -0.013 & 0.104 & 0.005 & 0.255 & 2973 & 18 \\
\hline & $(0.888)$ & $(0.041)$ & $(0.378)$ & $(0.694)$ & & & \\
\hline \multirow[t]{2}{*}{ utilities } & -0.077 & 0.014 & 0.016 & -0.024 & 0.294 & 3328 & 17 \\
\hline & $(0.250)$ & $(0.042)$ & $(0.840)$ & $(0.074)$ & & & \\
\hline
\end{tabular}


Table VI

\section{Sector returns and oil price volatility}

Panel A- Equation (1), Panel B: Equation (2) and Panel C: Equation (3)). Data is from 1988:12 through 2009:06. The dependent variable is the monthly excess returns of the sector stock market indexes in U.S. dollars. Explanatory variables include the world market return (world), positive variations of oil price returns (oilp), negative variations of oil price returns (oiln), currency variations against the U.S. dollar (currency). export is a dummy variable that assumes value of one when the country is an oil exporter country and zero otherwise. Oil price variations are computed using oil futures prices. Standard errors are clustered by country and are robust to heteroscedasticity. p-values are reported below coefficients.

\begin{tabular}{|c|c|c|c|c|c|c|c|c|c|}
\hline \multirow[b]{2}{*}{ sectors } & \multicolumn{9}{|c|}{ Panel A: Measure of volatility $\hat{\sigma}_{\text {garch }}$} \\
\hline & oilp & oiln & oilp·export & oiln·export & $\hat{\sigma}_{\text {garch }}$ & $\hat{\sigma}_{\text {garch }}$ export & Obs & Countries & $R^{2}$ \\
\hline \multirow[t]{2}{*}{ basicmat } & -0.056 & 0.070 & 0.103 & 0.101 & -0.018 & 0.169 & 4238 & 18 & 0.377 \\
\hline & $(0.009)$ & $(0.028)$ & $(0.080)$ & $(0.184)$ & $(0.650)$ & $(0.012)$ & & & \\
\hline \multirow[t]{2}{*}{ consgood } & -0.094 & 0.069 & 0.069 & 0.001 & -0.021 & 0.058 & 3950 & 18 & 0.197 \\
\hline & $(0.001)$ & $(0.016)$ & $(0.038)$ & $(0.978)$ & $(0.626)$ & $(0.362)$ & & & \\
\hline \multirow[t]{2}{*}{ consserv } & -0.099 & 0.017 & 0.134 & 0.038 & 0.018 & -0.037 & 4238 & 18 & 0.288 \\
\hline & $(0.000)$ & $(0.301)$ & $(0.001)$ & $(0.547)$ & $(0.635)$ & $(0.723)$ & & & \\
\hline \multirow[t]{2}{*}{ financials } & -0.078 & 0.025 & 0.099 & 0.046 & -0.143 & 0.096 & 4105 & 18 & 0.381 \\
\hline & $(0.000)$ & $(0.293)$ & $(0.047)$ & $(0.489)$ & $(0.028)$ & $(0.262)$ & & & \\
\hline \multirow[t]{2}{*}{ healthcare } & -0.035 & 0.029 & 0.070 & 0.072 & -0.033 & 0.040 & 3560 & 18 & 0.183 \\
\hline & $(0.018)$ & $(0.457)$ & $(0.124)$ & $(0.614)$ & $(0.351)$ & $(0.790)$ & & & \\
\hline \multirow[t]{2}{*}{ industrials } & -0.074 & 0.063 & -0.036 & 0.102 & -0.012 & 0.187 & 4017 & 18 & 0.292 \\
\hline & $(0.002)$ & $(0.009)$ & $(0.739)$ & $(0.288)$ & $(0.683)$ & $(0.129)$ & & & \\
\hline \multirow[t]{2}{*}{ oilgas } & 0.117 & 0.230 & 0.206 & -0.040 & -0.001 & -0.032 & 2861 & 17 & 0.296 \\
\hline & $(0.023)$ & $(0.000)$ & $(0.009)$ & $(0.578)$ & $(0.984)$ & $(0.790)$ & & & \\
\hline \multirow[t]{2}{*}{ technology } & -0.118 & 0.040 & -0.018 & 0.087 & 0.003 & 0.139 & 3113 & 15 & 0.282 \\
\hline & $(0.004)$ & $(0.394)$ & $(0.807)$ & $(0.275)$ & $(0.967)$ & $(0.041)$ & & & \\
\hline \multirow[t]{2}{*}{ telecom } & -0.123 & -0.058 & 0.060 & 0.169 & 0.081 & 0.025 & 2973 & 18 & 0.261 \\
\hline & $(0.001)$ & $(0.211)$ & $(0.099)$ & $(0.030)$ & $(0.293)$ & $(0.820)$ & & & \\
\hline \multirow[t]{4}{*}{ utilities } & -0.032 & 0.005 & -0.015 & 0.050 & -0.116 & 0.154 & 3328 & 17 & 0.295 \\
\hline & $(0.207)$ & $(0.856)$ & $(0.751)$ & $(0.342)$ & $(0.038)$ & $(0.047)$ & & & \\
\hline & \multicolumn{9}{|c|}{ Panel B: Measure of volatility $\hat{\sigma}_{\text {schwert }}$} \\
\hline & oilp & oiln & oilp·export & oiln·export & $\hat{\sigma}_{\text {schwert }}$ & $\hat{\sigma}_{\text {schwert }}$ export & Obs & Countries & $R^{2}$ \\
\hline \multirow[t]{2}{*}{ basicmat } & -0.006 & 0.015 & 0.038 & 0.174 & -0.077 & 0.127 & 4224 & 18 & 0.378 \\
\hline & $(0.835)$ & $(0.705)$ & $(0.524)$ & $(0.085)$ & $(0.018)$ & $(0.005)$ & & & \\
\hline \multirow[t]{2}{*}{ consgood } & -0.018 & -0.018 & 0.081 & -0.013 & -0.119 & -0.009 & 3940 & 18 & 0.200 \\
\hline & $(0.491)$ & $(0.546)$ & $(0.406)$ & $(0.909)$ & $(0.001)$ & $(0.952)$ & & & \\
\hline \multirow[t]{2}{*}{ consserv } & -0.042 & -0.048 & 0.044 & 0.138 & -0.083 & 0.129 & 4224 & 18 & 0.29 \\
\hline & $(0.101)$ & $(0.049)$ & $(0.298)$ & $(0.042)$ & $(0.003)$ & $(0.009)$ & & & \\
\hline \multirow[t]{2}{*}{ financials } & -0.050 & -0.006 & 0.052 & 0.095 & -0.067 & 0.086 & 4092 & 18 & 0.381 \\
\hline & $(0.010)$ & $(0.762)$ & $(0.325)$ & $(0.259)$ & $(0.016)$ & $(0.062)$ & & & \\
\hline \multirow[t]{2}{*}{ healthcare } & -0.007 & -0.003 & -0.035 & 0.194 & -0.048 & 0.168 & 3550 & 18 & 0.184 \\
\hline & $(0.782)$ & $(0.943)$ & $(0.451)$ & $(0.161)$ & $(0.187)$ & $(0.020)$ & & & \\
\hline \multirow[t]{2}{*}{ industrials } & -0.029 & 0.012 & -0.106 & 0.180 & -0.070 & 0.135 & 4003 & 18 & 0.292 \\
\hline & $(0.429)$ & $(0.738)$ & $(0.380)$ & $(0.031)$ & $(0.036)$ & $(0.026)$ & & & \\
\hline \multirow[t]{2}{*}{ oilgas } & 0.150 & 0.191 & 0.270 & -0.115 & -0.051 & -0.104 & 2853 & 17 & 0.297 \\
\hline & $(0.016)$ & $(0.001)$ & $(0.000)$ & $(0.443)$ & $(0.368)$ & $(0.392)$ & & & \\
\hline \multirow[t]{2}{*}{ technology } & -0.110 & 0.033 & -0.059 & 0.131 & -0.010 & 0.084 & 3104 & 15 & 0.283 \\
\hline & $(0.087)$ & $(0.574)$ & $(0.475)$ & $(0.142)$ & $(0.859)$ & $(0.156)$ & & & \\
\hline \multirow[t]{2}{*}{ telecom } & -0.027 & -0.172 & -0.093 & 0.347 & -0.137 & 0.243 & 2969 & 18 & 0.263 \\
\hline & $(0.525)$ & $(0.003)$ & $(0.072)$ & $(0.001)$ & $(0.027)$ & $(0.002)$ & & & \\
\hline utilities & -0.031 & 0.004 & -0.060 & 0.100 & -0.021 & 0.093 & 3321 & 17 & 0.295 \\
\hline & $(0.296)$ & $(0.935)$ & $(0.295)$ & $(0.243)$ & $(0.521)$ & $(0.133)$ & & & \\
\hline
\end{tabular}


Table VI

Sector returns and oil price volatility (cont.)

Panel A- Equation (1), Panel B: Equation (2) and Panel C: Equation (3)). Data is from 1988:12 through 2009:06. The dependent variable is the monthly excess returns of the sector stock market indexes in U.S. dollars. Explanatory variables include the world market return (world), positive variations of oil price returns (oilp), negative variations of oil price returns (oiln), currency variations against the U.S. dollar (currency). export is a dummy variable that assumes value of one when the country is an oil exporter country and zero otherwise. Oil price variations are computed using oil futures prices. Standard errors are clustered by country and are robust to heteroscedasticity. p-values are reported below coefficients.

\begin{tabular}{|c|c|c|c|c|c|c|c|c|c|}
\hline \multirow[b]{2}{*}{ sectors } & \multicolumn{9}{|c|}{ Panel C: Measure of volatility $\hat{\sigma}_{\text {square }}$} \\
\hline & oilp & oiln & oilp·export & oiln·export & $\hat{\sigma}_{\text {square }}$ & $\hat{\sigma}_{\text {square }} \cdot$ export & Obs & Countries & $R^{2}$ \\
\hline \multirow[t]{2}{*}{ basicmat } & 0.027 & -0.018 & 0.050 & 0.156 & -0.004 & 0.003 & 4238 & 18 & 0.379 \\
\hline & $(0.248)$ & $(0.580)$ & $(0.480)$ & $(0.023)$ & $(0.001)$ & $(0.034)$ & & & \\
\hline \multirow[t]{2}{*}{ consgood } & -0.031 & 0.000 & 0.046 & 0.023 & -0.003 & 0.001 & 3950 & 18 & 0.198 \\
\hline & $(0.232)$ & $(0.994)$ & $(0.412)$ & $(0.732)$ & $(0.020)$ & $(0.654)$ & & & \\
\hline \multirow[t]{2}{*}{ consserv } & -0.039 & -0.048 & 0.070 & 0.108 & -0.003 & 0.003 & 4238 & 18 & 0.289 \\
\hline & $(0.115)$ & $(0.106)$ & $(0.167)$ & $(0.018)$ & $(0.065)$ & $(0.279)$ & & & \\
\hline \multirow[t]{2}{*}{ financials } & -0.032 & -0.024 & 0.058 & 0.087 & -0.003 & 0.002 & 4105 & 18 & 0.38 \\
\hline & $(0.149)$ & $(0.151)$ & $(0.367)$ & $(0.228)$ & $(0.013)$ & $(0.145)$ & & & \\
\hline \multirow[t]{2}{*}{ healthcare } & 0.059 & -0.074 & -0.042 & 0.202 & -0.005 & 0.006 & 3560 & 18 & 0.188 \\
\hline & $(0.043)$ & $(0.054)$ & $(0.644)$ & $(0.153)$ & $(0.001)$ & $(0.224)$ & & & \\
\hline \multirow[t]{2}{*}{ industrials } & -0.040 & 0.026 & 0.035 & 0.024 & -0.002 & -0.002 & 4017 & 18 & 0.292 \\
\hline & $(0.271)$ & $(0.406)$ & $(0.824)$ & $(0.751)$ & $(0.114)$ & $(0.630)$ & & & \\
\hline \multirow[t]{2}{*}{ oilgas } & 0.197 & 0.134 & 0.197 & -0.028 & -0.004 & 0.000 & 2861 & 17 & 0.299 \\
\hline & $(0.000)$ & $(0.021)$ & $(0.000)$ & $(0.829)$ & $(0.036)$ & $(0.969)$ & & & \\
\hline \multirow[t]{2}{*}{ technology } & -0.160 & 0.087 & -0.110 & 0.192 & 0.002 & 0.005 & 3113 & 15 & 0.284 \\
\hline & $(0.004)$ & $(0.100)$ & $(0.291)$ & $(0.150)$ & $(0.268)$ & $(0.118)$ & & & \\
\hline \multirow[t]{2}{*}{ telecom } & -0.049 & -0.150 & -0.020 & 0.270 & -0.003 & 0.004 & 2973 & 18 & 0.262 \\
\hline & $(0.162)$ & $(0.002)$ & $(0.727)$ & $(0.000)$ & $(0.081)$ & $(0.142)$ & & & \\
\hline \multirow[t]{4}{*}{ utilities } & -0.010 & -0.020 & 0.003 & 0.029 & -0.002 & 0.000 & 3328 & 17 & 0.294 \\
\hline & $(0.635)$ & $(0.628)$ & $(0.968)$ & $(0.606)$ & $(0.154)$ & $(0.969)$ & & & \\
\hline & \multicolumn{9}{|c|}{ Panel D: Measure of volatility $\hat{\sigma}_{\text {gallant }}$} \\
\hline & oilp & oiln & oilp·export & oiln·export & $\hat{\sigma}_{\text {gallant }}$ & $\hat{\sigma}_{\text {gallant }} \cdot$ export & Obs & Countries & $R^{2}$ \\
\hline \multirow[t]{2}{*}{ basicmat } & -0.067 & 0.075 & 0.090 & 0.116 & 0.019 & 0.122 & 4168 & 18 & 0.382 \\
\hline & $(0.006)$ & $(0.040)$ & $(0.140)$ & $(0.173)$ & $(0.590)$ & $(0.010)$ & & & \\
\hline \multirow[t]{2}{*}{ consgood } & -0.091 & 0.062 & 0.080 & -0.006 & -0.019 & -0.022 & 3900 & 18 & 0.199 \\
\hline & $(0.001)$ & $(0.053)$ & $(0.015)$ & $(0.904)$ & $(0.648)$ & $(0.722)$ & & & \\
\hline \multirow[t]{2}{*}{ consserv } & -0.097 & 0.011 & 0.139 & 0.032 & -0.010 & -0.020 & 4168 & 18 & 0.29 \\
\hline & $(0.000)$ & $(0.537)$ & $(0.001)$ & $(0.581)$ & $(0.657)$ & $(0.752)$ & & & \\
\hline \multirow[t]{2}{*}{ financials } & -0.068 & 0.010 & 0.086 & 0.053 & -0.111 & 0.082 & 4040 & 18 & 0.383 \\
\hline & $(0.000)$ & $(0.633)$ & $(0.100)$ & $(0.400)$ & $(0.031)$ & $(0.183)$ & & & \\
\hline \multirow[t]{2}{*}{ healthcare } & -0.025 & 0.014 & 0.038 & 0.108 & -0.053 & 0.132 & 3510 & 18 & 0.185 \\
\hline & $(0.095)$ & $(0.714)$ & $(0.529)$ & $(0.467)$ & $(0.049)$ & $(0.338)$ & & & \\
\hline \multirow[t]{2}{*}{ industrials } & -0.083 & 0.066 & -0.029 & 0.092 & 0.012 & 0.047 & 3947 & 18 & 0.293 \\
\hline & $(0.003)$ & $(0.012)$ & $(0.777)$ & $(0.303)$ & $(0.660)$ & $(0.342)$ & & & \\
\hline \multirow[t]{2}{*}{ oilgas } & 0.119 & 0.221 & 0.197 & -0.033 & -0.016 & 0.006 & 2821 & 17 & 0.298 \\
\hline & $(0.016)$ & $(0.000)$ & $(0.010)$ & $(0.669)$ & $(0.723)$ & $(0.933)$ & & & \\
\hline \multirow[t]{2}{*}{ technology } & -0.117 & 0.041 & -0.020 & 0.087 & -0.005 & 0.079 & 3068 & 15 & 0.283 \\
\hline & $(0.004)$ & $(0.407)$ & $(0.815)$ & $(0.232)$ & $(0.928)$ & $(0.237)$ & & & \\
\hline \multirow[t]{2}{*}{ telecom } & -0.108 & -0.074 & 0.050 & 0.180 & -0.027 & 0.055 & 2953 & 18 & 0.26 \\
\hline & $(0.001)$ & $(0.159)$ & $(0.106)$ & $(0.020)$ & $(0.654)$ & $(0.513)$ & & & \\
\hline utilities & -0.018 & -0.011 & -0.031 & 0.063 & -0.105 & 0.103 & 3289 & 17 & 0.296 \\
\hline & $(0.507)$ & $(0.692)$ & $(0.517)$ & $(0.246)$ & $(0.024)$ & $(0.075)$ & & & \\
\hline
\end{tabular}




\section{Table VII: VAR Model: Relation between oil price volatility and asymmetry}

This table reports the estimations results of the VAR(2) model (Equation (4)). The sample ranges from 1988:12 to 2009:06. The dependent variables are the logarithms of the four volatility measures $\left(\hat{\sigma}_{\text {schwert }}, \hat{\sigma}_{\text {gallant }}, \hat{\sigma}_{\text {garch }}, \hat{\sigma}_{\text {square }}\right)$ and positive variations of oil futures returns (oilp), and negative variations of oil futures returns (oiln). Explanatory variables include past values of the previous variables.

\begin{tabular}{|c|c|c|c|c|c|c|c|c|}
\hline \multirow[t]{2}{*}{ Volatility Measures } & \multicolumn{2}{|c|}{$\ln \left(\hat{\sigma}_{\text {schwert }}\right)$} & \multicolumn{2}{|c|}{$\ln \left(\hat{\sigma}_{\text {gallant }}\right)$} & \multicolumn{2}{|c|}{$\ln \left(\hat{\sigma}_{\text {garch }}\right)$} & \multicolumn{2}{|c|}{$\ln \left(\hat{\sigma}_{\text {square }}\right)$} \\
\hline & Estimates & P-value & Estimates & P-value & Estimates & $\mathrm{P}$-value & Estimates & P-value \\
\hline $\ln (\hat{\sigma})$ & & & & & & & & \\
\hline $\ln (\hat{\sigma})_{t-1}$ & -0.028 & 0.726 & 1.003 & 0.000 & 0.775 & 0.000 & 0.039 & 0.645 \\
\hline $\ln (\hat{\sigma})_{t-2}$ & 0.908 & 0.248 & -0.207 & 0.001 & -0.09 & 0.474 & 0.124 & 0.140 \\
\hline $\ln \left(\right.$ oilp $_{t-1}$ & 0.053 & 0.429 & 0.036 & 0.013 & 0.077 & 0.000 & 0.092 & 0.550 \\
\hline $\ln (\text { oilp })_{t-2}$ & 0.103 & 0.122 & 0.013 & 0.350 & -0.004 & 0.664 & 0.075 & 0.624 \\
\hline $\operatorname{oiln}_{t-1}$ & -0.39 & 0.002 & -0.005 & 0.065 & -0.017 & 0.000 & -0.059 & 0.041 \\
\hline $\operatorname{oiln}_{t-2}$ & -0.005 & 0.707 & -0.005 & 0.052 & -0.000 & 0.841 & 0.001 & 0.967 \\
\hline Constant & 1.261 & 0.000 & 0.348 & 0.000 & 0.476 & 0.000 & 2.382 & 0.000 \\
\hline $\ln ($ oilp $)$ & & & & & & & & \\
\hline $\ln (\hat{\sigma})_{t-1}$ & 0.116 & 0.217 & -0.127 & 0.730 & -0.414 & 0.547 & 0.081 & 0.081 \\
\hline $\ln (\hat{\sigma})_{t-2}$ & -0.027 & 0.770 & 0.582 & 0.081 & 1.074 & 0.062 & 0.038 & 0.420 \\
\hline $\ln (\text { oilp })_{t-1}$ & 0.027 & 0.731 & 0.053 & 0.472 & 0.041 & 0.548 & -0.022 & 0.801 \\
\hline $\ln (\text { oilp })_{t-2}$ & 0.054 & 0.493 & -0.027 & 0.720 & 0.037 & 0.662 & -0.001 & 0.991 \\
\hline oiln $_{t-1}$ & 0.009 & 0.541 & 0.001 & 0.954 & 0.005 & 0.685 & 0.016 & 0.330 \\
\hline $\operatorname{oiln}_{t-2}$ & -0.005 & 0.726 & 0.010 & 0.470 & -0.005 & 0.771 & 0.005 & 0.776 \\
\hline Constant & 0.594 & 0.001 & -0.119 & 0.719 & -0.734 & 0.273 & 0.489 & 0.003 \\
\hline oiln & & & & & & & & \\
\hline $\ln (\hat{\sigma})_{t-1}$ & 0.655 & 0.184 & -1.988 & 0.314 & -8.751 & 0.016 & 0.225 & 0.362 \\
\hline $\ln (\hat{\sigma})_{t-2}$ & -0.703 & 0.151 & 1.375 & 0.443 & 6.367 & 0.036 & -0.313 & 0.205 \\
\hline $\ln \left(\operatorname{oilp}_{t-1}\right.$ & -0.343 & 0.408 & 0.019 & 0.961 & -0.030 & 0.935 & -0.291 & 0.518 \\
\hline $\ln (\text { oilp })_{t-2}$ & -0.044 & 0.916 & -0.144 & 0.717 & 0.336 & 0.458 & 0.016 & 0.971 \\
\hline oiln $_{t-1}$ & 0.277 & 0.000 & 0.188 & 0.015 & 0.217 & 0.001 & 0.264 & 0.002 \\
\hline $\operatorname{oiln}_{t-2}$ & 0.034 & 0.676 & 0.063 & 0.396 & -0.063 & 0.496 & 0.027 & 0.754 \\
\hline Constant & -1.753 & 0.062 & -0.975 & 0.583 & 2.440 & 0.492 & -1.686 & 0.049 \\
\hline
\end{tabular}


Table VIII: Granger Causality between oil price volatility and asymmetry and viceversa

This table reports Granger causality Wald tests. The sample ranges from 1988:12 to 2009:06. The column Granger causality describes the null hypothesis that the variable in this column does not Granger-cause the variable in the column denoted Equation. p-values of the test are reported in column $\mathrm{P}$-value.

\begin{tabular}{llrrrr}
\hline Volatility Measures & & $\ln \left(\hat{\sigma}_{\text {schwert }}\right)$ & $\ln \left(\hat{\sigma}_{\text {gallant }}\right)$ & $\ln \left(\hat{\sigma}_{\text {garch }}\right)$ & $\ln \left(\hat{\sigma}_{\text {square }}\right)$ \\
\hline Equation & Granger-Causality & P-value & P-value & P-value & P-value \\
\hline $\ln (\hat{\sigma})$ & $\ln ($ oilp$)$ & 0.218 & 0.033 & 0.000 & 0.746 \\
$\ln (\hat{\sigma})$ & oiln & 0.007 & 0.019 & 0.000 & 0.122 \\
$\ln (\hat{\sigma})$ & all & 0.012 & 0.030 & 0.000 & 0.288 \\
\hline $\ln ($ oilp $)$ & $\ln (\hat{\sigma})$ & 0.445 & 0.014 & 0.016 & 0.162 \\
$\ln ($ oilp $)$ & oiln & 0.799 & 0.764 & 0.896 & 0.575 \\
$\ln ($ oilp $)$ & all & 0.774 & 0.071 & 0.077 & 0.430 \\
\hline oiln & $\ln (\hat{\sigma})$ & 0.145 & 0.589 & 0.056 & 0.289 \\
oiln & $\ln ($ oilp$)$ & 0.705 & 0.934 & 0.756 & 0.811 \\
oiln & all & 0.312 & 0.781 & 0.155 & 0.501 \\
\hline
\end{tabular}


Table IX

\section{Stock market returns and oil (spot) price changes}

This table reports fixed effects panel regression estimations with interactions (Equations (1), (2) and (3)) from 1988:12 through 2009:06. The dependent variable is the monthly excess returns of stock market indexes in U.S. dollars. Explanatory variables include the world market return (world), positive variations of oil price returns (oilp), negative variations of oil price returns (oiln), currency variations against the U.S. dollar (currency), net oil price increases (nopi) and net oil price declines (nopd), scaled oil price increases (sopi) and scaled oil price declines (sopd), and volatility of oil spot prices $\left(\hat{\sigma}_{\text {schwert }}, \hat{\sigma}_{\text {gallant }}\right.$, $\left.\hat{\sigma}_{\text {garch }}, \hat{\sigma}_{\text {square }}\right)$. export is a dummy variable that assumes value of one when the country is an exporter country and zero otherwise. Oil price variations are computed using oil spot prices. Standard errors are clustered by country and are robust to heteroscedasticity. p-values are reported below coefficients.

\begin{tabular}{|c|c|c|c|}
\hline & (1) & $(2)$ & $(3)$ \\
\hline \multirow[t]{2}{*}{ world } & 0.920 & 0.926 & 0.924 \\
\hline & $(0.000)$ & $(0.000)$ & $(0.000)$ \\
\hline \multirow[t]{2}{*}{ currency } & 0.555 & 0.554 & 0.553 \\
\hline & $(0.000)$ & $(0.000)$ & $(0.000)$ \\
\hline \multirow[t]{2}{*}{ oilp } & -0.109 & & \\
\hline & $(0.000)$ & & \\
\hline \multirow[t]{2}{*}{ oiln } & 0.054 & & \\
\hline & $(0.004)$ & & \\
\hline \multirow[t]{2}{*}{ oilp·export } & 0.181 & & \\
\hline & $(0.000)$ & & \\
\hline \multirow[t]{2}{*}{ oiln.export } & 0.096 & & \\
\hline & $(0.113)$ & & \\
\hline \multirow[t]{2}{*}{ sopi } & & -0.841 & \\
\hline & & $(0.000)$ & \\
\hline \multirow[t]{2}{*}{ sopd } & & 0.259 & \\
\hline & & $(0.077)$ & \\
\hline \multirow[t]{2}{*}{ sopi·export } & & 1.591 & \\
\hline & & $(0.000)$ & \\
\hline \multirow[t]{2}{*}{ sopd-export } & & 0.945 & \\
\hline & & $(0.069)$ & \\
\hline \multirow[t]{2}{*}{ nopi } & & & -0.097 \\
\hline & & & $(0.000)$ \\
\hline \multirow[t]{2}{*}{ nopd } & & & 0.007 \\
\hline & & & $(0.046)$ \\
\hline \multirow[t]{2}{*}{ nopi-export } & & & 0.190 \\
\hline & & & $(0.011)$ \\
\hline \multirow[t]{2}{*}{ nopd·export } & & & 0.002 \\
\hline & & & $(0.732)$ \\
\hline \multirow[t]{2}{*}{ Constant } & 0.774 & 0.622 & 0.463 \\
\hline & $(0.000)$ & $(0.000)$ & $(0.000)$ \\
\hline Observations & 4238 & 4238 & 4238 \\
\hline Countries & 18 & 18 & 18 \\
\hline$R^{2}$ & 0.515 & 0.512 & 0.507 \\
\hline Test 1 & 50.420 & 36.960 & 19.790 \\
\hline $\mathrm{P}$-value & $(0.000)$ & $(0.000)$ & $(0.000)$ \\
\hline Test 2 & 32.010 & 22.130 & 9.980 \\
\hline $\mathrm{P}$-value & $(0.000)$ & $(0.000)$ & $(0.001)$ \\
\hline
\end{tabular}


Table X

\section{Stock market returns and oil (spot) price volatility}

This table reports fixed effects panel regression estimations with interactions (Equation (1), (2) and (3)) from 1988:12 through 2009:06. The dependent variable is the monthly excess returns of stock market indexes in U.S. dollars. Explanatory variables include the world market return (world), positive variations of oil price returns (oilp), negative variations of oil price returns (oiln), currency variations against the U.S. dollar (currency), net oil price increases (nopi) and net oil price declines (nopd), and volatility of oil spot prices $\left(\hat{\sigma}_{\text {schwert }}, \hat{\sigma}_{\text {gallant }}, \hat{\sigma}_{\text {garch }}\right.$, $\hat{\sigma}_{\text {square }}$ ). export is a dummy variable that assumes value of one when the country is an exporter country and zero otherwise. Oil price variations are computed using oil spot prices. Standard errors are clustered by country and robust to heteroscedasticity. p-values are reported below coefficients.

\begin{tabular}{|c|c|c|c|c|c|c|c|c|}
\hline & (1) & $(2)$ & $(3)$ & (4) & $(5)$ & $(6)$ & $(7)$ & $(8)$ \\
\hline \multirow[t]{2}{*}{ world } & 0.920 & 0.921 & 0.921 & 0.905 & 0.921 & 0.921 & 0.926 & 0.906 \\
\hline & $(0.000)$ & $(0.000)$ & $(0.000)$ & $(0.000)$ & $(0.000)$ & $(0.000)$ & $(0.000)$ & $(0.000)$ \\
\hline \multirow[t]{2}{*}{ currency } & 0.557 & 0.564 & 0.553 & 0.558 & 0.560 & 0.561 & 0.549 & 0.562 \\
\hline & $(0.000)$ & $(0.000)$ & $(0.000)$ & $(0.000)$ & $(0.000)$ & $(0.000)$ & $(0.000)$ & $(0.000)$ \\
\hline \multirow[t]{2}{*}{ oilp } & -0.144 & -0.113 & -0.102 & -0.043 & & & & \\
\hline & $(0.038)$ & $(0.000)$ & $(0.000)$ & $(0.339)$ & & & & \\
\hline \multirow[t]{2}{*}{ oiln } & 0.093 & 0.054 & 0.046 & -0.018 & & & & \\
\hline & $(0.227)$ & $(0.009)$ & $(0.014)$ & $(0.658)$ & & & & \\
\hline \multirow[t]{2}{*}{ oilp.export } & 0.188 & 0.148 & 0.155 & 0.172 & & & & \\
\hline & $(0.068)$ & $(0.000)$ & $(0.000)$ & $(0.032)$ & & & & \\
\hline \multirow[t]{2}{*}{ oiln.export } & 0.089 & 0.136 & 0.126 & 0.105 & & & & \\
\hline & $(0.525)$ & $(0.036)$ & $(0.036)$ & $(0.263)$ & & & & \\
\hline \multirow[t]{2}{*}{ nopi } & & & & & -0.061 & -0.097 & -0.079 & -0.046 \\
\hline & & & & & $(0.015)$ & $(0.001)$ & $(0.006)$ & $(0.044)$ \\
\hline \multirow[t]{2}{*}{ nopd } & & & & & 0.001 & 0.001 & 0.000 & -0.001 \\
\hline & & & & & $(0.873)$ & $(0.778)$ & $(0.934)$ & $(0.756)$ \\
\hline \multirow[t]{2}{*}{ nopi·export } & & & & & 0.196 & 0.173 & 0.134 & 0.204 \\
\hline & & & & & $(0.022)$ & $(0.017)$ & $(0.105)$ & $(0.028)$ \\
\hline \multirow[t]{2}{*}{ nopd·export } & & & & & 0.001 & 0.012 & 0.025 & -0.001 \\
\hline & & & & & $(0.839)$ & $(0.060)$ & $(0.008)$ & $(0.881)$ \\
\hline \multirow[t]{2}{*}{$\hat{\sigma}_{\text {schwert }}$} & 0.038 & & & & -0.063 & & & \\
\hline & $(0.548)$ & & & & $(0.000)$ & & & \\
\hline \multirow[t]{2}{*}{$\hat{\sigma}_{\text {schwert }} \cdot \operatorname{export}$} & -0.007 & & & & -0.011 & & & \\
\hline & $(0.950)$ & & & & $(0.757)$ & & & \\
\hline \multirow[t]{2}{*}{$\hat{\sigma}_{\text {gallant }}$} & & -0.001 & & & & -0.050 & & \\
\hline & & $(0.976)$ & & & & $(0.039)$ & & \\
\hline \multirow[t]{2}{*}{$\hat{\sigma}_{\text {gallant }} \cdot$ export } & & 0.109 & & & & 0.097 & & \\
\hline & & $(0.010)$ & & & & $(0.018)$ & & \\
\hline \multirow[t]{2}{*}{$\hat{\sigma}_{\text {garch }}$} & & & -0.047 & & & & -0.087 & \\
\hline & & & $(0.152)$ & & & & $(0.074)$ & \\
\hline \multirow[t]{2}{*}{$\hat{\sigma}_{\text {garch }} \cdot$ export } & & & 0.195 & & & & 0.276 & \\
\hline & & & $(0.015)$ & & & & $(0.013)$ & \\
\hline \multirow[t]{2}{*}{$\hat{\sigma}_{\text {square }}$} & & & & -0.003 & & & & -0.002 \\
\hline & & & & $(0.154)$ & & & & $(0.001)$ \\
\hline \multirow[t]{2}{*}{$\hat{\sigma}_{\text {square }} \cdot \operatorname{export}$} & & & & 0.000 & & & & -0.001 \\
\hline & & & & $(0.906)$ & & & & $(0.562)$ \\
\hline \multirow[t]{2}{*}{ Constant } & 0.770 & 0.608 & 0.759 & 0.524 & 0.766 & 0.614 & 0.601 & 0.489 \\
\hline & $(0.000)$ & $(0.000)$ & $(0.012)$ & $(0.001)$ & $(0.000)$ & $(0.000)$ & $(0.076)$ & $(0.000)$ \\
\hline Observations & 4224 & 4168 & 4238 & 4238 & 4224 & 4168 & 4238 & 4238 \\
\hline Countries & 18 & 18 & 18 & 18 & 18 & 18 & 18 & 18 \\
\hline$R^{2}$ & 0.516 & 0.52 & 0.516 & 0.516 & 0.511 & 0.511 & 0.509 & 0.511 \\
\hline Test 1 & 3.000 & 42.100 & 41.200 & 0.100 & 6.310 & 12.420 & 7.430 & 3.840 \\
\hline $\mathrm{P}$-value & $(0.101)$ & $(0.000)$ & $(0.000)$ & $(0.758)$ & $(0.022)$ & $(0.003)$ & $(0.014)$ & $(0.067)$ \\
\hline Test 2 & 7.550 & 31.510 & 28.920 & 5.260 & 4.650 & 10.710 & 8.630 & 3.610 \\
\hline $\mathrm{P}$-value & $(0.005)$ & $(0.000)$ & $(0.000)$ & $(0.017)$ & $(0.025)$ & $(0.001)$ & $(0.003)$ & $(0.049)$ \\
\hline
\end{tabular}


Table XI

\section{Stock Market Returns and Oil Price Changes-Subsamples}

This table reports fixed effects panel regression estimations (Equation (1), (2) and (3)) from 1988:12 through 2009:06. The dependent variable is the monthly excess returns of stock market indexes in U.S. dollars. Explanatory variables include the world market return (world), positive variations of oil price returns (oilp), negative variations of oil price returns (oiln), currency variations against the U.S. dollar (currency), net oil price increases (nopi) and net oil price declines (nopd). Oil price variations are computed using oil spot prices. Standard errors are clustered by country and are robust to heteroscedasticity. p-values are reported below coefficients.

\begin{tabular}{|c|c|c|c|c|c|c|}
\hline & Panel & 1: Oil-D & pendent Countries & Panel & Oil-E & untries \\
\hline & $(1)$ & $(2)$ & $(3)$ & $(4)$ & $(5)$ & $(6)$ \\
\hline world & 0.951 & 0.957 & 0.944 & 0.798 & 0.796 & 0.825 \\
\hline & $(0.000)$ & $(0.000)$ & $(0.000)$ & $(0.003)$ & $(0.003)$ & $(0.003)$ \\
\hline currency & 0.445 & 0.452 & 0.435 & 0.929 & 0.945 & 0.964 \\
\hline & $(0.000)$ & $(0.000)$ & $(0.000)$ & $(0.008)$ & $(0.006)$ & $(0.005)$ \\
\hline oilp & -0.086 & & & 0.066 & & \\
\hline & $(0.000)$ & & & $(0.149)$ & & \\
\hline oiln & 0.038 & & & 0.133 & & \\
\hline & $(0.032)$ & & & $(0.056)$ & & \\
\hline sopi & & -0.802 & & & 0.572 & \\
\hline & & $(0.000)$ & & & $(0.044)$ & \\
\hline sopd & & 0.299 & & & 0.986 & \\
\hline & & $(0.102)$ & & & $(0.123)$ & \\
\hline nopi & & & -0.105 & & & 0.074 \\
\hline & & & $(0.001)$ & & & $(0.289)$ \\
\hline nopd & & & 0.008 & & & 0.003 \\
\hline & & & $(0.036)$ & & & $(0.710)$ \\
\hline Constant & 0.544 & 0.560 & 0.396 & 0.979 & 0.953 & 0.775 \\
\hline & $(0.000)$ & $(0.000)$ & $(0.000)$ & $(0.000)$ & $(0.000)$ & $(0.001)$ \\
\hline Observations & 3185 & 3185 & 3185 & 1053 & 1053 & 1053 \\
\hline Countries & 13 & 13 & 13 & 5 & 5 & 5 \\
\hline$R^{2}$ & 0.533 & 0.532 & 0.531 & 0.496 & 0.490 & 0.482 \\
\hline Test 1 & 37.010 & 19.740 & 22.590 & 9.320 & 1.670 & 1.630 \\
\hline $\mathrm{P}$-value & $(0.000)$ & $(0.001)$ & $(0.001)$ & $(0.038)$ & $(0.266)$ & $(0.270)$ \\
\hline Test 2 & 11.290 & 16.840 & 11.290 & 4.870 & 8.560 & 0.950 \\
\hline $\mathrm{P}$-value & $(0.000)$ & $(0.000)$ & $(0.002)$ & $(0.085)$ & $(0.036)$ & $(0.458)$ \\
\hline
\end{tabular}


Table XII

\section{Stock market returns and oil price volatility-Subsamples}

This table reports fixed effects panel regression estimations (Equations (1), (2) and (3)) from 1988:12 through 2009:06. The dependent variable is the monthly excess returns of stock market indexes in U.S. dollars. Explanatory variables include the world market return (world), positive variations of oil price returns (oilp), negative variations of oil price returns (oiln), currency variations against the U.S. dollar (currency), net oil price increases (nopi) and net oil price declines (nopd) and volatility of oil futures prices $\left(\hat{\sigma}_{\text {schwert }}, \hat{\sigma}_{\text {gallant }}, \hat{\sigma}_{\text {garch }}, \hat{\sigma}_{\text {square }}\right)$. Oil price variations are computed using oil futures prices. Standard errors are clustered by country and are robust to heteroscedasticity. p-values are reported below coefficients.

\begin{tabular}{|c|c|c|c|c|c|c|c|c|}
\hline & \multicolumn{8}{|c|}{ Panel A: Oil- Dependent Countries } \\
\hline & $(1)$ & $(2)$ & $(3)$ & $(4)$ & $(5)$ & $(6)$ & $(7)$ & $(8)$ \\
\hline \multirow[t]{2}{*}{ world } & 0.950 & 0.951 & 0.952 & 0.938 & 0.941 & 0.942 & 0.945 & 0.930 \\
\hline & $(0.000)$ & $(0.000)$ & $(0.000)$ & $(0.000)$ & $(0.000)$ & $(0.000)$ & $(0.000)$ & $(0.000)$ \\
\hline \multirow[t]{2}{*}{ currency } & 0.451 & 0.448 & 0.441 & 0.453 & 0.446 & 0.440 & 0.433 & 0.448 \\
\hline & $(0.000)$ & $(0.000)$ & $(0.000)$ & $(0.000)$ & $(0.000)$ & $(0.000)$ & $(0.000)$ & $(0.000)$ \\
\hline \multirow[t]{2}{*}{ oilp } & -0.057 & -0.079 & -0.079 & -0.043 & & & & \\
\hline & $(0.019)$ & $(0.000)$ & $(0.000)$ & $(0.089)$ & & & & \\
\hline \multirow[t]{2}{*}{ oiln } & 0.006 & 0.026 & 0.030 & -0.008 & & & & \\
\hline & $(0.781)$ & $(0.109)$ & $(0.080)$ & $(0.666)$ & & & & \\
\hline \multirow[t]{2}{*}{ nopi } & & & & & -0.075 & -0.092 & -0.088 & -0.055 \\
\hline & & & & & $(0.003)$ & $(0.002)$ & $(0.005)$ & $(0.016)$ \\
\hline \multirow[t]{2}{*}{ nopd } & & & & & 0.003 & 0.001 & 0.002 & 0.001 \\
\hline & & & & & $(0.370)$ & $(0.794)$ & $(0.752)$ & $(0.849)$ \\
\hline \multirow[t]{2}{*}{$\hat{\sigma}_{\text {schwert }}$} & -0.044 & & & & -0.056 & & & \\
\hline & $(0.084)$ & & & & $(0.001)$ & & & \\
\hline \multirow[t]{2}{*}{$\hat{\sigma}_{\text {gallant }}$} & & -0.038 & & & & -0.061 & & \\
\hline & & $(0.053)$ & & & & $(0.029)$ & & \\
\hline \multirow[t]{2}{*}{$\hat{\sigma}_{\text {garch }}$} & & & -0.057 & & & & -0.070 & \\
\hline & & & $(0.055)$ & & & & $(0.108)$ & \\
\hline \multirow[t]{2}{*}{$\hat{\sigma}_{\text {square }}$} & & & & -0.002 & & & & -0.002 \\
\hline & & & & $(0.078)$ & & & & $(0.013)$ \\
\hline \multirow[t]{2}{*}{ Constant } & 0.660 & 0.789 & 1.045 & 0.448 & 0.686 & 0.771 & 0.939 & 0.407 \\
\hline & $(0.000)$ & $(0.000)$ & $(0.002)$ & $(0.000)$ & $(0.000)$ & $(0.001)$ & $(0.009)$ & $(0.000)$ \\
\hline Observations & 3174 & 3130 & 3185 & 3185 & 3174 & 3130 & 3185 & 3185 \\
\hline Countries & 13 & 13 & 13 & 13 & 13 & 13 & 13 & 13 \\
\hline$R^{2}$ & 0.534 & 0.536 & 0.534 & 0.535 & 0.534 & 0.535 & 0.532 & 0.534 \\
\hline Test 1 & 3.090 & 42.290 & 33.040 & 0.940 & 13.010 & 12.850 & 9.200 & 6.950 \\
\hline $\mathrm{P}$-value & $(0.104)$ & $(0.000)$ & $(0.000)$ & $(0.350)$ & $(0.004)$ & $(0.004)$ & $(0.015)$ & $(0.023)$ \\
\hline Test 2 & 4.630 & 34.980 & 25.560 & 3.430 & 6.850 & 9.570 & 8.010 & 4.300 \\
\hline P-value & $(0.032)$ & $(0.000)$ & $(0.000)$ & $(0.067)$ & $(0.010)$ & $(0.003)$ & $(0.000)$ & $(0.039)$ \\
\hline
\end{tabular}


Table XII

Stock market returns and oil price changes and oil price volatility-Subsamples (cont.)

This table reports fixed effects panel regression estimations (Equation 1, 2 and 3) from 1988:12 through 2009:06. The dependent variable is the monthly excess returns of stock market indexes in U.S. dollars. Explanatory variables include the world market return (world), positive variations of oil price returns (oilp), negative variations of oil price returns (oiln), currency variations against the U.S. dollar (currency), net oil price increases (nopi) and net oil price declines (nopd) and volatility of oil futures prices $\left(\hat{\sigma}_{\text {schwert }}, \hat{\sigma}_{\text {gallant }}, \hat{\sigma}_{\text {garch }}, \hat{\sigma}_{\text {square }}\right)$. Oil price variations are computed using oil futures prices. Standard errors are clustered by country and are robust to heteroscedasticity. p-values are reported below coefficients.

\begin{tabular}{|c|c|c|c|c|c|c|c|c|}
\hline & \multicolumn{8}{|c|}{ Panel B: Oil-Exporter Countries } \\
\hline & $(1)$ & $(2)$ & $(3)$ & $(4)$ & $(5)$ & $(6)$ & $(7)$ & $(8)$ \\
\hline \multirow[t]{2}{*}{ world } & 0.798 & 0.795 & 0.798 & 0.792 & 0.822 & 0.819 & 0.824 & $\overline{0.809}$ \\
\hline & $(0.003)$ & $(0.003)$ & $(0.003)$ & $(0.003)$ & $(0.003)$ & $(0.003)$ & $(0.003)$ & $(0.003)$ \\
\hline \multirow[t]{2}{*}{ currency } & 0.928 & 0.944 & 0.934 & 0.930 & 0.970 & 0.979 & 0.966 & 0.964 \\
\hline & $(0.008)$ & $(0.006)$ & $(0.007)$ & $(0.007)$ & $(0.004)$ & $(0.004)$ & $(0.004)$ & $(0.005)$ \\
\hline \multirow[t]{2}{*}{ oilp } & 0.052 & 0.051 & 0.055 & 0.089 & & & & \\
\hline & $(0.266)$ & $(0.190)$ & $(0.241)$ & $(0.158)$ & & & & \\
\hline \multirow[t]{2}{*}{ oiln } & 0.149 & 0.146 & 0.145 & 0.106 & & & & \\
\hline & $(0.058)$ & $(0.049)$ & $(0.040)$ & $(0.131)$ & & & & \\
\hline \multirow[t]{2}{*}{ nopi } & & & & & 0.102 & 0.072 & 0.050 & 0.133 \\
\hline & & & & & $(0.231)$ & $(0.313)$ & $(0.515)$ & $(0.158)$ \\
\hline \multirow[t]{2}{*}{ nopd } & & & & & -0.002 & 0.002 & 0.012 & -0.006 \\
\hline & & & & & $(0.805)$ & $(0.742)$ & $(0.147)$ & $(0.502)$ \\
\hline \multirow{2}{*}{$\hat{\sigma}_{\text {schwert }}$} & 0.021 & & & & -0.057 & & & \\
\hline & $(0.395)$ & & & & $(0.061)$ & & & \\
\hline \multirow[t]{2}{*}{$\hat{\sigma}_{\text {gallant }}$} & & 0.057 & & & & 0.001 & & \\
\hline & & $(0.146)$ & & & & $(0.949)$ & & \\
\hline \multirow[t]{2}{*}{$\hat{\sigma}_{\text {garch }}$} & & & 0.100 & & & & 0.104 & \\
\hline & & & $(0.170)$ & & & & $(0.208)$ & \\
\hline \multirow[t]{2}{*}{$\hat{\sigma}_{\text {square }}$} & & & & -0.001 & & & & -0.003 \\
\hline & & & & $(0.449)$ & & & & $(0.084)$ \\
\hline \multirow[t]{2}{*}{ Constant } & 0.925 & 0.563 & 0.101 & 0.924 & 1.078 & 0.720 & -0.026 & 0.800 \\
\hline & $(0.000)$ & $(0.054)$ & $(0.846)$ & $(0.001)$ & $(0.000)$ & $(0.013)$ & $(0.966)$ & $(0.000)$ \\
\hline Observations & 1050 & 1038 & 1053 & 1053 & 1050 & 1038 & 1053 & 1053 \\
\hline Countries & 5 & 5 & 5 & 5 & 5 & 5 & 5 & 5 \\
\hline$R^{2}$ & 0.498 & 0.502 & 0.497 & 0.496 & 0.485 & 0.488 & 0.483 & 0.486 \\
\hline Test 1 & 3.670 & 9.330 & 11.760 & 0.060 & 2.240 & 1.430 & 0.310 & 3.380 \\
\hline $\mathrm{P}$-value & $(0.128)$ & $(0.038)$ & $(0.027)$ & $(0.813)$ & $(0.209)$ & $(0.297)$ & $(0.608)$ & $(0.140)$ \\
\hline Test 2 & 3.430 & 4.810 & 6.700 & 2.720 & 1.620 & 0.910 & 1.630 & 2.010 \\
\hline $\mathrm{P}$-value & $(0.135)$ & $(0.086)$ & $(0.053)$ & $(0.180)$ & $(0.305)$ & $(0.474)$ & $(0.304)$ & $(0.249)$ \\
\hline
\end{tabular}

